\title{
Intergenerational Effects of Employment Protection Reforms
}

\author{
Jenifer Ruiz-Valenzuela*†
}

October 2019

\begin{abstract}
Job insecurity has worsened in most OECD countries in the aftermath of the Great Recession. Using Labour Force Survey data, I estimate the link between parental job insecurity (as measured by the contract type held by parents) and children's school related outcomes. Endogeneity issues affecting the type of contract held by parents are dealt with by constructing an instrument based on regional, time and demographic variation in the amount of wage subsidies available to firms to convert fixed-term contracts into permanent ones in Spain. The findings suggest that children whose fathers are less job insecure are considerably more likely to graduate from compulsory education on time. They are also less likely to drop out of the education system and be classified as Not in Education, Employment or Training at age sixteen. Employment protection reforms that liberalise the use of fixed-term contracts and do not take into account these negative externalities on other members of the household are therefore understating their overall cost.
\end{abstract}

JEL Classification: J65, I20, I24

Keywords: employment protection, fixed-term contracts, job insecurity, intergenerational impacts, school outcomes

\footnotetext{
${ }^{*}$ Centre for Economic Performance, London School of Economics. Email: j.ruiz-valenzuela@1se.ac.uk

${ }^{\dagger}$ I am grateful to Andrea Ichino and Jérôme Adda for their advice, and to Libertad González, Sandra McNally and Peter Skogman Thoursie for comments on previous versions of this paper. I would also like to thank Rodrigo Ceni, José Ignacio García Pérez, Claudia Hupkau, Daniel Ritter and Ernesto Villanueva, and conference and seminar participants at the European University Institute, the 26th EALE conference, the XVII Spanish Applied Economics Meetings, the Bank of Slovenia and CaixaBank Research. I am also very grateful to Michele Pellizzari and anonymous referees for their helpful comments. All remaining errors are my own.
} 


\section{Introduction}

Job insecurity has increased in most OECD countries in the aftermath of the Great Recession (OECD, 2016) and, as a consequence, so has the fear of losing one's job. ${ }^{1}$ Job insecurity has been a defining feature of some European countries for several decades. After the reforms that took place in the Eighties as a way to introduce flexibility into the labour market, economies like Spain, France or Italy developed a dual labour market structure with two easily identifiable sets of workers. As opposed to workers with permanent (or open-ended) contracts, those with fixed-term (or temporary) contracts suffer greater exposure to the risk of job loss since the latter, by definition, have a predetermined expiration date. Moreover, further increases in job insecurity are likely in the current context of 'uberisation' of the economy and the appearance of zero-hour contracts. While some degree of flexibility is needed for firms to adjust to the economic cycle, job insecurity can be harmful to affected workers. In particular, fixedterm contracts have been shown to lead to lower wages, lower levels of job satisfaction, lower levels of physical and mental health and increased occupational mismatch, among other negative consequences. ${ }^{2}$ The negative consequences of job insecurity are likely to spill over onto other members of the household, in particular children. This paper analyses the intergenerational impact of job insecurity by investigating how the contractual arrangement of working parents affects children's school related outcomes. To the best of my knowledge, this is the first article that tries to identify the causal effect of parental contractual form on children's outcomes.

Some of the negative consequences of fixed-term contracts affect variables that are normally considered to be inputs affecting the production function of cognitive achievement. These include impacts on parental income, parental time investments and parent's mental health. Lower levels of income associated with fixed-term contracts could affect the financial resources devoted to children's education (Blau, 1999). Job insecurity could also be linked to a reduction of the time spent with children if job insecure parents need to devote a disproportionately higher amount of time to look for a more secure job (Becker, 1993). Additionally, it could be difficult to isolate children from the negative consequences on parent's mental health that could be derived from insecure employment conditions. ${ }^{3}$

The estimation of a causal relationship between parent's contract type and child schooling outcomes faces two main obstacles. First, it is uncommon to find linked parent-child datasets with rich data of

\footnotetext{
${ }^{1}$ As Green (2015) explains, "the phrase 'job insecurity' refers mainly to the fear of losing one's job. For some, however, the expression is broader and refers to the possibility of some sort of degradation of status in a job without actually being made redundant, such as being transferred to a less interesting or less challenging post with the same employer".

${ }^{2}$ See the summaries of the empirical literature by Bentolila et al. (2008) and Dolado et al. (2002); as well as the studies by Booth et al. (2002), Guadalupe (2003), Green (2015) and Bartoll et al. (2018).

${ }^{3}$ As Duncan and Brooks-Gunn (2000) point out, some studies have shown that parent mental health accounts for some of the impact of economic circumstances on child health and behavior. Also, poor parent mental health is associated with impaired parent-child interactions and fewer learning experiences in the home.
} 
parental labour market characteristics and detailed school performance. To overcome this obstacle, I use data from the Spanish Labour Force Survey (LFS), that allows linking all members living in the same household at the time of the interview. Given that all members aged sixteen or higher reply to the individual questionnaire, I can construct broad variables measuring school related outcomes. In particular, the information in the Spanish LFS allows the researcher to measure whether an individual has finished compulsory education on time at age sixteen; whether the student is not observed in the education system once she has reached the legal age to drop out; and the even more pervasive outcome capturing whether the student is not in education, employment or training (NEET) at the age of sixteen. All these indicators make poor employment and earnings prospects more likely in the longer term, among other potentially negative consequences. ${ }^{4}$

The second challenge to estimating a causal relationship between parent's contract type and child related outcomes is related to the fact that the type of contract under which any of the parents is hired is likely correlated with unobserved parental and household characteristics that also affect schooling outcomes of the child. ${ }^{5}$ This paper uses exogenous variation in regional labour market policies in Spain to identify the causal effects of interest. As Dolado et al. (2002) put it, "if one looks for a country to test for the different effects of temporary work contracts on the labour market, Spain provides a fascinating case study". After the 1984 liberalisation reform, the use of fixed-term contracts in Spain suffers a substantial increase. Figure 1 shows that from the first year of data available in 1987, the fixed-term employment rate increases steadily from about $15 \%$ in 1987 to over $30 \%$ in the early 1990's.

After this dramatic increase in fixed-term contracts, several national reforms in the 1990's and early 2000's tried to reverse the situation. From 1997, also some regional governments introduced different programs aiming to increase the fraction of permanent contracts. In practice, these programs consisted of introducing regional wage subsidies as a way to offer incentives to firms to convert fixed-term contracts into permanent contracts. Not all regional governments implemented them, and among the regional governments that designed subsidies to foster permanent employment, the amount of the subsidy varied between different demographic groups and across time. I adapt the strategy followed in Barceló and Villanueva (2016), who study the impact of contract type on household financial wealth, to construct an instrument for the contract type held by the father when the student is sixteen years old. ${ }^{6}$ In particular, the instrument is constructed using subsidy variation across region, gender, time and age of the worker at

\footnotetext{
${ }^{4}$ For instance, Cook and Kang (2016) show that drop out mediates criminal involvement.

${ }^{5}$ Examples of variables typically unavailable in standard datasets include measures of parental productivity or motivation at work. Both variables could affect the likelihood of parents being able to get a permanent contract and the school performance of the child.

${ }^{6}$ Ideally, one would want to observe the type of contract of the father at least at several points in time during the school life of the child. Unfortunately, the cross-section version of the Spanish Labour Force Survey, needed to observe the specific age of the individual, does not allow to link responses of individuals in different quarters.
} 
the time of hiring. First stage estimates suggest that the amount of regional subsidies available to convert fixed-term contracts into permanent contracts had a positive and significant impact on the likelihood of holding permanent contracts. A battery of robustness checks suggest that the instrument is strong for fathers, whereas it is rather weak when trying to predict maternal's contract type. Therefore the analysis in this paper focuses mainly on the role of father's contract type on school related outcomes of the child.

The results show that students whose fathers hold a permanent contract (as opposed to a temporary or fixed-term contract) are, on average, about 7.8 percentage points more likely to graduate on time. They are also less likely to drop out of education at age sixteen by about 2.5 percentage points, and there is suggestive evidence indicating that they are less likely to be classified as NEET by about 1.6 percentage points. These magnitudes are sizeable and represent, respectively, about $37 \%, 19 \%$ and $23 \%$ of the initial raw difference in these outcomes between individuals whose fathers have a permanent versus a fixed-term contract (and about 16\%, 9\% and 7.5\% of the overall standard deviation of the outcome, respectively). Robustness checks show that the main results in this paper are not driven by parents with recent experiences of unemployment.

I explore potential mechanisms for the negative effects of father's fixed-term contract. The results suggest that fathers with fixed-term contracts want to work more hours. Additionally, fathers on fixedterm contracts show significantly lower levels of job satisfaction in several aspects of their jobs; in particular with respect to satisfaction with job stability. Big differential effects in job satisfaction are likely to be felt at the household level. In fact, work in social psychology has shown that children as young as 5 years of age can develop clear perceptions of the world of work and parent's job insecurity, and understand concepts such as pay, labor disputes, unemployment and welfare (Barling et al., 1999).

Temporality and unemployment spells are frequently alternated by job insecure workers. As a result, this paper is linked to the literature analysing the intergenerational effects of parental unemployment. A recent paper in this literature is the one by Pinger (2016), that finds that paternal unemployment has a considerable negative effect on the probability to complete upper secondary education. The impact of parental unemployment also seems to affect life satisfaction of children (Nikolova and Nikolaev, 2018). Workers with fixed-term contracts, in the absence of contract conversion, are faced with job loss at the termination date. Therefore, the results in the job loss literature are also relevant to this paper. Examples of negative impacts of parental job loss on school performance include Rege et al. (2011), who show negative impacts of parental job loss due to plant closure in Norway, and Ruiz-Valenzuela (2015) who shows negative effects of job losses stemming from the Great Recession in Spain. ${ }^{7}$

\footnotetext{
${ }^{7}$ Other papers analysing the impact of parental unemployment and parental job loss are summarised in the literature reviews of Pinger (2016) and Ruiz-Valenzuela (2015).
} 
Even if the effects reported in this paper might seem large, other papers in this related literature have also found rather large effects for the impact of paternal unemployment or paternal job loss on children's outcomes. For instance, using data from Germany, Pinger (2016) finds that parental unemployment at the time of the upper secondary education decision reduces the probability of obtaining a higher education certificate by about one third. Another example in the job loss literature, by Rege et al. (2011), finds that paternal job loss has a negative effect on graduating secondary students' school performance in Norway, reducing graduation-year GPA by about $6 \%$ of the standard deviation overall (11\% of the standard deviation in municipalities with mediocre performing job markets).

The remainder of the paper is organised as follows. Section 2 describes the Spanish labour market and the institutional framework in place during the eighties, nineties and early 2000's. Section 3 describes the data, whereas Section 4 presents the empirical strategy. The main results, robustness checks and potential mechanisms are discussed in Section 5. Section 6 concludes.

\section{The Spanish labour market: Institutional framework}

In 1984, with an unemployment rate above 20\%, the Spanish government promoted a major change in Employment Protection Legislation (EPL) that entailed the liberalisation of fixed-term employment contracts for regular jobs. ${ }^{8}$ This new framework extended the use of fixed-term contracts to all type of jobs for a maximum duration of three years. ${ }^{9}$

There are two main differences between permanent and fixed-term contracts. First, fixed-term contracts entail much lower severance payments. At the time, workers hired on a permanent contract would receive 45 days' wages per year of seniority (with a limit of 42 months' wages) for unfair dismissals. ${ }^{10}$ Once expired, fixed-term contracts entailed no compensation. Second, fixed-term contracts cannot be appealed upon termination (i.e., the worker cannot sue the employer for wrongful termination). As Barceló and Villanueva (2016) explain, there are no other differences between permanent and fixedterm contracts in terms of contributions to retirement pensions, access to unemployment benefits or to medical services.

After the dramatic increase in fixed-term contracts that followed the 1984 reform (see available data

\footnotetext{
${ }^{8}$ Details about the institutional framework in this section come from Dolado et al. (2002), García-Pérez and Rebollo Sanz (2009), Méndez (2013), Barceló and Villanueva (2016) and Garcia-Perez et al. (2018).

${ }^{9}$ In practice, this legal limit was often not respected; and this is still the case nowadays. For instance, in September 2016 the European Court of Justice ruled in favour of a nurse that had been continuously employed with different fixed-terms contracts in a hospital in Madrid since February 2009 to June 2013 (here). Following concern about the incidence of this malpractice, the summer of 2018 the Spanish government has set in place an initiative to reduce this type of fraud (here).

${ }^{10}$ This was 20 days' wages for fair dismissals. According to Galdon-Sanchez and Guell (2000), of the cases that ended up in court between 1986 and 1998, judges ruled in favour of the worker in above $70 \%$ of them (i.e., they were considered unfair dismissals).
} 
from 1987 in Figure 1), several national reforms in the 1990's and early 2000's tried to reverse the situation. Méndez (2013) provides a good summary of these reforms. The most relevant reform in the 1990's took place in 1997. The main change was the creation of a new permanent contract with lower severance payments for unfair dismissals (33 days's wages per year of seniority with a maximum of 24 months of wages), that could be used for most new hires (see Dolado et al. (2002)).

From 1997, regional governments introduced different programs aiming to increase the fraction of permanent contracts. In practice, these programs consisted of introducing regional wage subsidies as a way to offer incentives to firms to hire workers on permanent contracts. ${ }^{11}$ Subsidies were granted to firms that converted an existing fixed-term contract into a permanent one. ${ }^{12}$ These subsidies were granted as a lump-sum in the year the conversion took place. Only 3 regions had subsidies in place in 1997, but by 2004 all regions (except Navarra and Catalonia) had had some form of subsidy in place for at least one year. The amount of regional subsidies available to firms also varied by age and gender of workers. Importantly, within regions, the presence and amount of regional subsidies varied across years. Therefore, firms and workers could not know with certainty whether those incentives would be available in the future, so it was very difficult for firms or workers to act strategically. Figure 2, borrowed from Barceló and Villanueva (2016), shows the amount of subsidies available for conversion of fixed-term contracts into permanent contracts by region, between 1997 and 2004. Amounts varied substantially across regions, years and demographic groups. For instance, the statutory amount ranged from 1500 euros for males in Valencia in 2003; to more than 14000 euros if the person whose contract was converted to a permanent contract was older than 46 in Extremadura in $1999 .{ }^{13}$ Changes in the amount of regional subsidies available by region, gender, age group at hire and year of hire serve as the basis on which I build an instrumental variable for whether the father/mother has a permanent contract in the year their child turns sixteen. More details about the construction of the instrument, as well as a discussion of the assumptions needed for its validity, are provided in Section 4.

\footnotetext{
${ }^{11}$ García-Pérez and Rebollo Sanz (2009) and Barceló and Villanueva (2016) offer a good description of these programs. Borrowing from these articles, I summarise the main aspects here and refer the reader to the cited articles for a more in-depth account.

${ }^{12}$ There were also subsidies to hire unemployed workers under a permanent contract, although its use was much lower than that of contract conversions.

${ }^{13}$ Data in García-Pérez and Rebollo Sanz (2009) and Barceló and Villanueva (2016) show that the net present value of the subsidy is about 12 to $16 \%$ of yearly labour costs, and that 4 to $6 \%$ of new jobs lasting at least 2 years could have benefited from a subsidised conversion.
} 


\section{Data}

The main dataset used in this paper comes from the cross-section version of the Spanish Labour Force Survey. More details about the size and structure of the dataset are given in the Data Appendix, Section A1.

Graduation from compulsory education in Spain takes place during the year the student turns sixteen, as long as she graduates on time. The academic year in Spain starts in September and finishes in June. Therefore, I use data from the fourth quarter of the year in which the individual turns sixteen to understand whether he or she has graduated from compulsory education on time. In particular, I use data collected in the fourth quarter of the years 2000 to 2004. This particular period is chosen for two reasons. First, from the academic year starting in September 1999, all students turning sixteen in the Spanish education system are under the law that extended compulsory education from age fourteen to age sixteen (Ley Orgánica de Ordenación General del Sistema Educativo or LOGSE). ${ }^{14}$ Second, the data on regional subsidies used to construct the instrument is available until 2004.

The year of birth is used to identify those individuals turning sixteen in each year. I match the resulting observations with the personal and labour market characteristics of their parents. The population of interest is formed by 4907 individuals that live with fathers that have a fixed-term or a permanent contract in the fourth quarter of the year in which the child should graduate from compulsory education. ${ }^{15}$ The final pooled working sample is formed by 4737 individuals ( $96.5 \%$ of the initial available sample) who live with both their parents, and whose fathers are aged 34 to 65 in the year of observation. ${ }^{16}$ The sample includes workers hired before regional subsidies were in place (i.e., before 1997). As Barceló and Villanueva (2016) point out, even if workers hired before 1997 do not provide identification of the impact of regional subsidies to contract conversion, including them in the sample reduces the estimated variance of the remaining parameters both in the first and second stage equations. Section A1 in the Data Appendix describes how the main variables used in the analysis are constructed.

In the main working sample, $81 \%$ of fathers are hired on a permanent contract in the quarter when their children should have graduated from compulsory education (if they do so on time). ${ }^{17}$ Table 1

\footnotetext{
${ }^{14}$ Before 1999, different implementation rhythms of the law (across regions, provinces and even municipalities) make it impossible to distinguish in the data whether a student stating to have completed compulsory education has done so at age fourteen (old system) or at age sixteen (new system).

${ }^{15}$ There are 10284 individuals turning sixteen from 2000 to 2004 in the data, but only 9141 are sixteen at the time of the interview. There are 4907 individuals whose fathers have a permanent or fixed-term contract. The remaining fathers are self-employed (1907), unemployed (376), inactive (388) or retired (300). A total of 1263 individuals do not live in the same household as the father the year they turn sixteen.

${ }^{16}$ Also, excluded from the sample are those individuals that live in the autonomous cities of Ceuta and Melilla.

${ }^{17}$ Grade retention in Spain is not rare. According to PISA data for 2003, about $6 \%$ of students have repeated at least one grade during primary education; and $25 \%$ have repeated at least a grade during secondary education.
} 
shows mean outcomes for individuals aged sixteen whose fathers have a permanent contract (column 1), a fixed-term contract (column 2) and for all the sample (column 3). About $58 \%$ of individuals in the sample graduated on time from compulsory education; $8.5 \%$ are not observed in any kind of education, and close to 5\% are NEET. Individuals whose fathers have a fixed-term contract the year they turn sixteen are about 21 percentage points less likely to graduate on time than those with fathers with a permanent contract. The differences are also big for the other two outcomes: individuals with fathers hired under a fixed-term contract are about 13 percentage points more likely to have dropped out from the education system; and 7 percentage points more likely to be classified as NEET.

These big differences in school-related outcomes should not come as a surprise. Fathers hired under permanent and fixed-term contracts are different. The descriptive statistics in Table 2 show that fathers hired under a permanent contract are about 30 percentage points more likely to have a post-compulsory education degree and are more likely to be Spanish nationals. They also have been working at the current firm for longer (17 versus 2 years of tenure, on average), work in bigger firms and are more likely to work in the public sector. The data does not include an earnings variable, but data from other surveys overwhelmingly shows that individuals hired under permanent contracts also have higher earnings. ${ }^{18}$

Panel D in Table 2 shows average data for the instrumental variable. Following Barceló and Villanueva (2016), the instrument is calculated as the average amount of subsidies available to convert fixed-term contracts into permanent contracts during the first two years at the firm. I estimate this amount using the number of years the father has been employed at the current job, the age when he entered the firm and the region of residence (NUTS 2). ${ }^{19}$ The average subsidy over the first two years at the firm is used because most contract conversions take place in months 12 and 13 after being hired (Güell and Petrongolo, 2007). Subsidies are converted into constant euro of year 2000 using regional deflators of household gross disposable income. For workers hired before 1997, the instrument takes value zero. This is why the average amount available to convert fixed-term contracts into permanent ones during the first two years at the firm is much lower for fathers hired under permanent contracts.

Finally, the Spanish section of the European Household Panel (available for years 1994 to 2001) is used to understand differences by contract type related to satisfaction with several aspects of the job. This data will be used in Section 5 when discussing mechanisms. More details are given in the Data Appendix, Section A2.

\footnotetext{
${ }^{18}$ According to data from the 2002, 2005 and 2008 waves of the Spanish Survey of Household Finances, households whose head has a permanent contract have $62 \%$ higher earnings on average (Barceló and Villanueva, 2016).

${ }^{19}$ As Barceló and Villanueva (2016) explain "subsidies to contract conversion are not directly related to hiring decisions, as firms can always hire a worker with a fixed-term contract and subsequently decide whether or not to continue rolling it over".
} 


\section{Empirical Strategy}

The empirical strategy followed here is adapted from Barceló and Villanueva (2016) to tailor it to the specific context given by the research question and the data used in this paper. I start by studying the impact of the average amount of subsidy available during the first two years at the firm on the type of contract held by the father (first stage), and on the three children outcomes (reduced form). The linear first stage and reduced form equations are first estimated by Ordinary Least Squares (OLS) models:

$$
\begin{aligned}
Y_{i}=\alpha_{0}+ & \alpha_{1} * \text { Subsidy }_{R, a, t_{0}}+\sum_{a=1}^{4} \alpha_{2, a} \text { AgeHire }_{a}+\sum_{R=1}^{16} \alpha_{3, R} \text { Region }_{R}+ \\
& +\alpha_{4} \text { Tenure }+\alpha_{5} \text { Tenure }^{2}+\alpha_{6} \text { Tenure }^{3}+X^{\prime} \alpha_{7}+\epsilon
\end{aligned}
$$

where $Y_{i}$ is a dummy variable for student $i$ indicating whether the father has a permanent contract in the first stage equation; and a dummy for the outcome variable of interest in the reduced form equation. I have omitted the subindex $i$ in all the variables on the right hand side to simplify notation. The amount of subsidies $\left(\right.$ Subsid $_{R, a, t_{0}}$ ) varies at the region (R) level, age of the father at hiring (a) and year of hire $\left(t_{0}\right)$. As a result, the model includes 16 NUTS- 2 region dummies, as well as 4 age group dummies for the father, that are defined on the basis of the statutory age cutoffs. In order to compare workers/fathers who entered the firm during the same year, I control flexibly for father's tenure by introducing in the model a third order polynomial in tenure, as well as survey year dummies. Finally, I introduce a post-1997 contract dummy capturing whether the father signed the current contract on or after 1997. This controls for the main national reform that took place in 1997 and introduced a new set of open-ended contracts. By doing so, $\alpha_{1}$ captures mainly regional variation in the availability of subsidies to incentivise permanent contracts. Table 3, column 1, presents the basic controls added in this first specification. $\epsilon$ is clustered at the level of definition of the instrument, i.e. at the level of definition of the subsidy $\left(R, a, t_{0}\right)$.

In a second specification (Table 3, column 2) I add further controls: three dummies capturing the level of education of the father, and the sector of activity of the firm he works for. All these variables belong to the second stage, and should not impact the magnitude of $\alpha_{1}$ substantially. Including them, however, can help to improve precision of the estimates and the power of the instrument.

The last (and preferred) specification shown in Table 3, column 3, includes variables related to the specific question in this paper. This specification additionally controls for the gender and quarter of birth of the child and the father's nationality. It also controls for the youth unemployment rate in the region, defined in the year the student turns sixteen. Finally, this last specification also includes the 
amount of regional subsidies available to hire individuals in the age range of the student in the year she turns sixteen. If the timing and amount of regional subsidies available to hire individuals at age 16 were correlated with the timing and amount of subsidies available to hire fathers, it would be crucial to control for this variable.

Other than these regional policies on subsidies available to hire young people under permanent contracts that I can and do control for, it is unlikely that there exists other regional policies implemented at the same time and targeting the same group of people (which is defined by age at hire and year of hire), that would vary at the same level and could affect both contract conversion of fathers and school related outcomes of children.

As Barceló and Villanueva (2016) point out, the identification assumption in Equation 1 is that "in the absence of the subsidy, the probability that an employer decides to upgrade a fixed-term contract into a high firing cost one for a worker of a given age in a particular year would be similar across regions". This implicitly assumes the impact on contract conversion of the second and third order interactions (between the region dummies, age dummies, and the third order tenure polynomial) to be zero. For identification purposes, it would be enough to assume so for the third order interaction. I test those assumptions by checking how the coefficient of interest $\alpha_{1}$, both in the first stage and reduced forms, varies when including second order interactions. The results of a series of other additional robustness checks is shown in Section 5, as well as results of placebo exercises.

I first estimate the first stage and reduced form equations in a linear setting. This allows me to compare the results of the first stage using the Spanish Labour Force Survey data, to those obtained by Barceló and Villanueva (2016) using the Spanish Survey of Household Finances. The linear setting also allows me to test for weak instruments when errors are not homoscedastic. ${ }^{20}$ The linear first stage and reduced form are per se informative and allow testing for weak instruments, but do not take into account that both the outcome(s) and the endogenous regressor in this paper are binary variables. Given this, I then estimate simultaneous equation bivariate probit models, where the probability of the father having a permanent contract and the child finishing compulsory education on time (or not being in education or being NEET) are jointly estimated. The model can be written as follows (again, I have omitted the subindex $i$ in all the variables on the right hand side to simplify notation):

$$
\begin{gathered}
P_{i}=1\left[\alpha_{0}+\alpha_{1} * \text { Subsidy }_{R, a, t_{0}}+\sum_{a=1}^{4} \alpha_{2, a} \text { AgeHire }_{a}+\sum_{R=1}^{16} \alpha_{3, R} \text { Region }_{R}+\right. \\
\left.+\alpha_{4} \text { Tenure }+\alpha_{5} \text { Tenure }^{2}+\alpha_{6} \text { Tenure }^{3}+X^{\prime} \alpha_{7}+v_{i}>0\right]
\end{gathered}
$$

\footnotetext{
${ }^{20}$ I follow Andrews et al. (2018) who argue that "with a single endogenous regressor, we recommend that researchers judge instrument strength based on the effective F-statistic of Montiel Olea and Pflueger (2013)".
} 


$$
\begin{gathered}
Y 16_{i}=1\left[\beta_{0}+\beta_{1} P_{i}+\sum_{a=1}^{4} \beta_{2, a} \text { AgeHire }_{a}+\sum_{R=1}^{16} \beta_{3, R} \text { Region }_{R}+\right. \\
\left.+\beta_{4} \text { Tenure }+\beta_{5} \text { Tenure }^{2}+\beta_{6} \text { Tenure }^{3}+X^{\prime} \beta_{7}+\epsilon_{i}>0\right]
\end{gathered}
$$

where Equation 2 is the bivariate probit first stage and $\left(\epsilon_{i}, v_{i}\right)$ is distributed as bivariate normal with $\rho=\operatorname{Corr}\left(\epsilon_{i}, v_{i}\right) . \quad P_{i}$ is a dummy variable equal to 1 if the father has a permanent contract; and $Y 16_{i}$ is any of the three binary outcomes of interest. Parameters in the model are estimated by maximum likelihood, and standard errors are robust and clustered at the level of definition of the regional subsidies. Given normality of the error components, the model is identified if $\left(\epsilon_{i}, v_{i}\right)$, conditional on covariates, is independent of $S u b s i d y_{R, a, t_{0}}$.

As long as the model is correctly specified, the bivariate probit model can be used to estimate average causal effects (Angrist and Pischke, 2008). For each model, I present the results of a Wald test for the absence of correlation in the model under the null hypothesis. If the null cannot be rejected, I report parameters of a restricted model with $\rho=0$. The best one can do without a distributional assumption (and moving to a linear setting), is to estimate Local Average Treatment Effects (LATE), the average causal effect for compliers. Two-stage least squares estimates are presented too, followed by a discussion about complier's characterisation.

A final concern regarding the estimation strategy used in this paper is related to the timing at which the outcomes and the paternal contract status are observed. ${ }^{21}$ This is especially the case for the graduation on time outcome, since not graduating on time can potentially be the result of several years of low educational achievements. Absence of on time graduation in the data can be due to: (1) not graduating at all even in the absence of any grade repetition; (2) graduating at a later date because the student has been retained in at least one grade. Unfortunately, the Labour Force Survey data does not allow for the identification of whether the student is graduating late because she has repeated a grade earlier in life, or because she fails to pass a grade in secondary school, prior to graduation. According to 2003 PISA data, grade repetition in Spain happened mainly during compulsory secondary education: 25.02\% of 15-year old pupils who have repeated a grade at least once have done so during compulsory secondary education, whereas $6.34 \%$ of them have repeated a grade at least once during primary education. Accordingly, I would expect that grade repetition in the sample happens mostly during compulsory secondary edu-

\footnotetext{
${ }^{21}$ Ideally, one would want to observe the type of contract of the father at least at several points in time during the school life of the child. Unfortunately, the cross-section version of the Spanish Labour Force Survey, needed to observe the specific age of the individual, does not allow to link responses of individuals in different quarters. Additionally, fathers with a permanent contract at the end of compulsory education will have been exposed to this type of contract for a different number of years depending on when the contract started. Unfortunately, the sample size available poses a poblem for the identification strategy when trying to work with smaller subsamples; i.e. the instrument is not strong enough when dividing the sample into different exposure bins.
} 
cation, a period in which regional subsidies (i.e. the instrument) were already in place. Additionally, fathers could hold permanent or fixed-term contracts for reasons stemming from several years back in the past. Instrumental variable (IV) estimates would take care of this issue, since, as already mentioned before, the effect that IV identifies is the causal effect for compliers. ${ }^{22}$ In the case of this study, these would be the children of fathers who hold a permanent contract in the year of graduation precisely because they were affected by the regional subsidies instrument. Therefore, IV estimates would identify the effect only for those students for whom the timing is correct.

\section{Results}

\subsection{On time graduation}

\subsubsection{Intention to Treat estimates}

Table 4 shows the impact of the instrument (i.e., the average statutory subsidy amount for contract conversions available in the first two years at the firm, in thousands of euros) on the probability that the father has a permanent contract (Panel A); and the probability that the child graduates from compulsory education on time (Panel B). Columns 1 to 3 show the results of the different specifications described in Section 4 and summarised in Table 3.

The results shown in Panel A are virtually the same across all specifications. An increase of 1000 euros in the average subsidy available increases the chances of observing the father with a permanent contract by about 2 percentage points (from an average share of permanent contracts in the sample of about $81 \%$ ). These estimates are similar to the 1.5 percentage point estimate obtained by Barceló and Villanueva (2016) using the Spanish Survey of Household Finances and the group of males aged above 40 (i.e., the group that is the most similar to the sample of fathers analysed here). The instrument becomes stronger as more controls are added and the precision of the estimated coefficient for the instrumental variable increases. Given that standard errors are clustered at the subsidy cell level, I use the (more stringent) test developed by Pflueger and Wang (2015) to test for weak instruments under non-homoscedastic errors. Setting the confidence level to 5\%, the effective F test in column 3 needs to be compared to the critical values under different values of $\tau$ (i.e., fraction of a "worst case scenario" situation in which the instruments are completely uninformative and first- and second-stage errors are perfectly correlated). The test rejects the null for a weak instrument threshold of $\tau=20 \%$ (in fact, the effective $\mathrm{F}$ stat lies between the critical values of $\tau=10 \%$ and $\tau=20 \%$ ). These results show that the

\footnotetext{
${ }^{22}$ This holds under the assumption of no defiers. That is, there is no individual that would hold a permanent contract when he is not eligible to regional subsidies, and that would hold a temporary contract when he is eligible to regional subsidies.
} 
instrument is reasonably strong in this preferred specification.

The results in Panel B show the reduced form impacts: an increase of 1000 euros in the incentive to raise the father's job protection increases the chances of finishing compulsory education on time by about 1 percentage point. The average amount of the instrument in regions and years with positive subsidies in the sample is about 3300 euros. This implies that for the average subsidy during those years, the reduced form impact of the regional subsidies on the probability of graduating from compulsory education on time was above 3 percentage points. This can be compared with a mean on time graduation rate of about $41 \%$ for children whose fathers have a fixed-term contract.

The average amount of regional subsidies available to hire mothers during the first two years at the firm also have an impact on the probability that the mother holds a permanent contract. Table 5, Panel A, shows that an increase of 1000 euros in the average subsidy available to mothers increases the probability of observing the mother with a permanent contract by about 1 percentage point. In this case though, and even if the instrument is significant at conventional levels, the null for a weak instrument cannot be rejected even for $\tau=30 \%$ in any of the specifications. Additionally, the reduced form coefficients in Panel B show no direct effect of the instrument on the probability of on time graduation. The raw difference in the sample in terms of on time graduation between individuals whose mothers have a fixed-term versus a permanent contract is $8.5 \%$ in favour of the latter. However, this difference entirely disappears in the OLS regressions shown in Panel C, when I further control for the different set of controls specified in Table 3. These results show that after controlling for the variables in the basic specification in column 1, there is no additional impact of the mother's contract type on the probability of graduating from compulsory education on time. I will show later in this section that this is not the case for father's contract type. The remainder of the paper focuses therefore on the impact of the father's contract type. Differential effects by parental gender will be discussed when analysing potential mechanisms in Section 5.4.

As discussed in Section 4, the identification strategy relies on the assumption that the impact on contract conversion of the second and third order interactions (between the region dummies, father's age dummies, and the third order polynomial in father's tenure) is zero. However, for identification purposes, it would be enough to assume so for the third order interaction. Following Barceló and Villanueva (2016), I test the assumption by checking how the coefficient of interest $\alpha_{1}$ varies when including second order interactions sequentially, both for the first stage and the reduced form, using the preferred specification (Table 4, column 3). The results are shown in Table 6. The first stage coefficient for the instrument varies in magnitude when adding the second order interactions sequentially (Table 6, Panel A), for instance to 1.5 percentage points when all second order interactions are included (column 4). 
This compares to 2.2 percentage points in the preferred specification (i.e. in the absence of second order interactions) but it is significant at the (almost) $1 \%$ level and within the $95 \%$ confidence interval of the coefficient shown for the preferred specification. Moreover, out of the 124 second order interactions in this more stringent specification; only $15 \%$ are significant at the 5\% level in the first stage. Doing the same exercise for the reduced form, almost none of the two-way interactions (3\%) have a direct significant impact on the probability of on-time graduation; while the instrument remains significant and of slightly higher magnitude (Table 6, Panel B). As in Barceló and Villanueva (2016), these results suggest that shocks correlated with pairwise interaction effects between region, age at-hire and tenure do not change substantially the impact of incentives to contract conversion on contract form or on-time graduation from compulsory education.

A series of additional robustness checks for the first stage equation are presented in Table 7. All these robustness checks are ran using the preferred specification, which is shown again in column 1. For simplicity, this is the specification that I will use from now on.

The main models estimated here depart slightly from the strategy in Barceló and Villanueva (2016). The latter include year of hire fixed effects rather than controlling flexibly for tenure as is done here. The results in column 2 show how the regional subsidies coefficient changes when the first stage equation includes year of hire fixed effects (instead of the third order polynomial in father's tenure). There is still a positive effect (and significant at the $10 \%$ level) on the probability of having a permanent contract. But given the decrease in magnitude and precision, the instrument becomes weak. The results suggest that adding year of hire fixed effects is probably too demanding for the sample size available here.

Regional subsidies available to hire the father in the first two years at the firm could be correlated with the average amount of regional subsidies available to hire the mother. Even if the results in Table 5 suggest no direct effect of the latter on the probability of on-time graduation, it is reassuring to see that the coefficient on the mean subsidy in the first two years of tenure of the father is not altered when including the mean subsidy available to mothers (column 3). Also, the average amount available to hire mothers under permanent contracts in the first two years at the firm has no impact on whether the father holds a permanent contract. These results in column 3 keep the sample constant by setting the amount of regional subsidies equal to zero for those mothers not in work. I restrict the sample to those students with both parents working in column 4 . The results go in the same direction.

Garcia-Perez et al. (2018) show that workers that entered the labour market just after the national 1984 reform suffered negative impacts on the number of days worked and earnings over the first 10 years in the labour market, and that yearly earning losses amounted to a persistent $7.3 \%$ over 27 years of labour market career. In Column 5, I include a dummy for whether the father entered the labour market 
after 1984 to control for potential correlation between the 1984 national reform, the regional policies and the probability of holding a permanent contract. The first stage coefficient remains significant and of the same size as in the original specification in Column 1. Moreover, workers in the public sector should not be affected by the availability of regional subsidies since these were granted to firms. Therefore, excluding public workers from the sample should not alter the results, as shown in column 6 .

All the results so far have not made use of the sample weights. As Solon et al. (2015) have shown, when the purpose of the analysis is to estimate causal effects, it is not straightforward that one should use weights, and they therefore suggest showing both weighted and unweighted results. Column 7 shows that the results barely change when using sample weights.

In column 8 , I construct a binary instrument instead, based on whether the firm could receive the regional wage subsidy if the contract of the father would be upgraded to a permanent one. This binary eligibility instrument is equal to one as long as there is a positive amount of regional subsidies available. The results show that eligible fathers are 8.3 percentage points more likely to hold a permanent contract. The instrument based on the amount of regional subsidies exploits a greater amount of information in the data, and as such is more informative and its effective F statistic in column 1 higher. Therefore, the instrument based on the amount rather than merely on eligibility is preferred.

The same robustness checks are performed on the reduced form equation. The results are presented in Table 8, with a very similar structure to the one described for the previous section. As before, results are less precise in the more demanding specification that controls for year of hire fixed effects. Also, when the sample size is considerable reduced by excluding students with unemployed mothers. But all in all, the results are in line with those in the preferred specification.

The results of placebo experiments, when the timing of the subsidies is assigned incorrectly, are shown in Table 9. The amount of the subsidy available to convert fixed-term contracts to permanent contracts 2 years before being hired by the firm has a null impact on both the first stage (column 1) and reduced form (column 2). Even the amount available one year before (that could be correlated with the average amount available in the first two years at the firm) has a very small impact in the first stage, and shows no significant impact in the reduced form.

A different placebo test can be performed by using a sample of workers with older children, whose educational outcomes are predetermined at the time the subsidies were in place. No reduced form impact should be found for such a sample. This is what is shown in Table 10: there is no effect of the regional subsidies available to hire fathers with permanent contracts on whether children of 19 (column 1) or 20 years of age (column 2 ) have completed compulsory education. ${ }^{23}$.

\footnotetext{
${ }^{23}$ By that age, most individuals would have completed secondary education if they are to complete it at all
} 
All in all, the results of the robustness checks presented in Tables 6, 7 and 8 and the placebo experiments shown in Tables 9 and 10 suggest that the average amount available to the firm to convert fixed-term contracts to permanent contracts during the first two years of worker's tenure is a valid instrumental variable for father's contract type.

\subsubsection{OLS, Bivariate probit and Two-Stage Least Squares}

As was shown in Table 1, the on-time graduation raw difference between students whose fathers have a permanent and a fixed-term contract is 21 percentage points in favour of the first group. Table 11 shows that a big part of this difference is explained by the control variables included in the preferred specification. The OLS results presented in column 1 show that students whose fathers have a permanent contract are 8.2 percentage points more likely to graduate from compulsory education on time. Even if the set of controls is rich (I am holding constant characteristics such as the father's level of education, tenure and sector of work), the type of contract under which the father is hired could still potentially be correlated with unobserved individual and household characteristics that also affect schooling outcomes of the child. Columns 2 and 3 in Table 11 try to address this. Results are shown for the preferred specification.

In column 2, I present the results of estimating simultaneous equation bivariate probit models to take into account the fact that both the outcome variable and the endogenous variable of interest are binary. The results in Panel A show the impact of the father's contract type on the probability of on time graduation. The average marginal impact of having a father with a permanent contract is about 7.8 percentage points. This is about $37 \%$ of the initial raw difference. The results in Panel B show the impact of the instrument on the probability that the father has a permanent contract and go in the same direction as those found in the linear setting (although the magnitude is smaller).

IV estimates of the effect of having a father holding a permanent contract the year the child should graduate from compulsory education are considerably larger than bivariate probit average marginal effects, with IV estimates showing an estimated impact of around 51 percentage points in column 3. Due to the lower precision of the IV estimates though, the bivariate probit average marginal effect falls within the 95\% IV confidence interval. As Chiburis et al. (2012) point out, discrepancies between bivariate probit and IV point estimates are not uncommon. This is especially the case in models with covariates (see also Angrist and Pischke (2008)), in small samples (which Chiburis et al. (2012) define as smaller than 5000 observations) and when treatment probabilities are close to 0 or 1 . The two latter reasons might apply here since the sample falls within their small sample criteria, and the probability of treatment is 0.81 , i.e. $81 \%$ of fathers in the samples have a permanent contract. 
Most importantly, and as discussed in Section 4, the IV estimator captures the effect of compliers. In the case of the present study, the IV estimator offers a weighted local average treatment effect for those students whose fathers hold a permanent contract due to the availability of regional subsidies at the time of hiring whereas bivariate probit estimates capture average marginal effects instead. Compliers are, therefore, individuals whose fathers got a permanent contract due to the existence of regional subsidies but that otherwise would have been observed holding a temporary contract in the year the child should graduate from compulsory education. As a result, one could think that for compliers, the inputs in the 'school performance production function' affected by father's contract status would suffer a bigger change when moving from a temporary to a permanent contract. A simple theoretical model can provide intuition to understand this bigger effect for compliers, and can be found in Appendix B.

An additional exercise that can help understand the differential effect for compliers follows the methodology proposed in Angrist and Pischke (2008) on counting and characterising compliers. For the purpose of this exercise, it is useful to use the binary elegibility instrument defined in the previous section. This instrument is based on whether the firm could receive the regional wage subsidy if the contract of the father would be upgraded to a permanent one, and it is equal to one as long as there is a positive amount of regional subsidies available in the region of residence of the father, taking into account the father's age at hire and year of hire. Table 12 shows different probabilities of compliance in Panel A, as well as other magnitudes that are necessary to compute those. The size of the overall complier group, which equals $8.3 \%$ in the preferred specification, is given by the first stage. The proportion of fathers that are treated (i.e. hold a permanent contract) is $81.4 \%$ and the probability that the instrument is switched on is $17.6 \%$. With these two magnitudes and the size of the overall complier group, the proportion of the treated who are compliers can be calculated. This is given by the first stage, times the probability the instrument is switched on, divided by the proportion treated. The size of this group is small (close to $2 \%$ of the treated are compliers) and can well explain the divergence between average marginal effects of temporary contracts, and local average treatment effects for this subpopulation of compliers (which would be different from the subpopulation of compliers given by another potential instrument).

Panel B in Table 12 offers some insights into what this specific population of compliers looks like. As Angrist and Pischke (2008) describe, the relative likelihood that a complier has a certain characteristic is given by the ratio of the first stage for compliers with that characteristic to the overall first stage. Panel B shows subgroup first stages in the first column, and the relative likelihood for compliers to have that given characteristic in the second column. The most salient characteristic of compliers in this paper is that they are more likely to have post-compulsory education. They are also more likely to be older than 45 and live in areas with above median unemployment rates. That effects are bigger for this particular 
subpopulation of compliers chimes well with a recent paper using Spanish data before and during the Great Recession (Bartoll et al., 2018). Their results suggest that working in a temporary job tends to incrementally increase work stress among the male population, with especially detrimental effects for older salaried workers and those with a university degree, who they argue may be more sensitive to changes in the labour market due to the failure of expectations about work.

\subsection{Other outcomes: Not in Education and NEET at age 16}

The analysis so far has focused on the impact of father's contract type on the probability of graduating from compulsory education on time. Absence of on-time graduation in the data can be due to: (1) graduating at a later date because the student has been retained in at least one grade; (2) not graduating at all even in the absence of any grade repetition. Both reasons, grade repetition and failure to graduate from compulsory education, could lead students to drop out of the education system altogether. The outcomes analysed in this section capture whether the student is not observed in the education system once she has reached the legal age to drop out; and the even more pervasive outcome capturing whether the student is not in education, employment or training at the age of sixteen. Using the preferred specification (controls described in column 3 of Table 3), the OLS results in Table 13, Column 1, show that after controlling for a rich set of variables, individual's whose fathers have a permanent contract are 5 percentage points less likely to drop out of the education system at sixteen. They are also about 3 percentage points less likely to be NEET at sixteen.

Given that the average in the sample for these outcomes is concentrated in the tails (see Table 1), I show results addressing potential endogeneity concerns from bivariate probit regressions in column 2 of Table 13. The magnitude of the estimates is almost halved with respect to the linear OLS estimates in column 1, but the effect is still sizeable compared to the average in the sample and the mean outcome for students whose fathers are hired on fixed-term contracts. Students whose fathers have a permanent contract are about 2.5 percentage points less likely to drop out of education at sixteen; and 1.6 percentage points less likely to become NEET at age sixteen ( $\mathrm{p}$-value $=0.161$ ). The results are less precise than those found for the on-time graduation outcome, but still of considerable magnitude to provide suggestive evidence that those children whose father has a permanent contract are less likely to both drop out and become NEET at sixteen. ${ }^{24}$

\footnotetext{
${ }^{24} \mathrm{IV}$ estimates are, like with the on time graduation outcome, bigger for the subgroup of compliers (-0.238 (SE: 0.188) and -0.187 (SE: 0.134) for the Not in Education and NEET outcome, respectively.
} 


\subsection{Fixed-Term contracts versus unemployment}

Fathers with a fixed-term contract are more likely to be unemployed in the year prior to observation (both in the working sample and the bigger sample). About $15 \%$ of fathers with fixed-term contracts were unemployed in the previous year, as opposed to about $0.5 \%$ of fathers with permanent contracts. This is one of the most salient differences observed between fathers holding fixed-term versus permanent contracts. The literature has shown that temporality and unemployment are likely to go hand in hand in Spain. In fact, Garcia-Perez et al. (2018) have found that the long-term impact of fixed-term contracts on worker's careers is likely to be negative. These authors find that those starting out their labour market career right after the liberalisation of fixed-term contracts in Spain are more likely to spend more time in unemployment ( $4.9 \%$ lower number of days worked over the first ten years in the labour market).

The identification strategy used in this paper should already take care of the correlation between unemployment and temporality. I run an additional check to assess whether fathers with recent unemployment spells are driving the results. Specifically, I re-run the intergenerational analysis excluding those fathers that were unemployed one year before the year of observation. Table 14, columns 3 and 4, show the results. For comparison, I also present OLS and bivariate probit results using the full sample in columns 1 and 2. Excluding fathers with recent unemployment spells barely affect the results (although magnitudes are slightly bigger, with the resulting positive impact in the precision of estimates). The average marginal impact of having a father with a permanent contract increases the probability of on-time graduation by 8.2 percentage points, while it decreases the probability of dropping out of the education system at sixteen by 3.2 percentage points. Both estimates are significant at conventional levels. The estimates also suggest that having a father with a permanent contract makes their children 2 percentage points less likely to be observed in the NEET category.

\subsection{Discussing potential mechanisms}

Fathers employed on fixed-term contracts might have a different amount of time available outside work hours to spend with their children. Among other reasons, this could be due to differences in the number of hours worked or the time invested in looking for another (potentially more stable) job. I use information in the Spanish LFS to understand whether variables capturing these differences could be driving the results. The first column in Table 15 shows mean outcomes for fathers with a fixed-term contract, whereas column 2 shows the raw difference in the mean outcome for fathers with permanent contracts in the sample. There are no raw statistically significant differences in the normal weekly hours worked or in the deviation of (weekly) normal versus current hours worked in the sample. It is less likely, 
though, that fathers with a permanent contract want to work more hours or are looking for another job. In columns 3 and 4, I repeat the same exercise but working with a larger sample by including all those fathers with children living at home with ages between sixteen and twenty. ${ }^{25}$ This allows me to increase the sample to almost 28000 fathers (with slightly above 5000 of them holding a fixed-term contract in the year of observation). The averages for fathers with fixed-term contracts shown in column 3 , and the raw differences shown in column 4 are very similar to those obtained for the working sample in columns 1 and 2. This shows the stability of both mean outcomes and raw differences in much bigger samples. Given that these raw differences could be explained by observed differences in other parental characteristics, I show how those initial raw differences change when accounting for all the set of controls used throughout the paper and described in Table 3, column 4 (with the exception of controls that specifically account for children characteristics). This is shown in column 5. After accounting for the rich set of controls, fathers with a permanent contract are about 1 percentage point less likely to want to work more hours, and 2.6 percentage points less likely to be looking for another job. These are non-negligible magnitudes, expecially if one compares them with the average values implied by Columns 3 and 4 . In terms of working hours, fathers with a permanent contract are more likely to work more (more than half an hour more per week).

The identification strategy used in the main analysis can also be used for the analysis of potential mechanisms. Results for the second stage, using the preferred specification, are shown in Column $6 .^{26}$ Most of the raw differences seen between fathers with permanent and fixed-term contracts do not hold in this setting. All in all, these results suggest that there are no big differences in the number of weekly hours worked (or in deviations from contractual hours), but that there might be some differences in variables that could be related with how satisfied fathers are with the current conditions of their job. Fathers with fixed-term contracts want to work more hours, for instance; and the results suggest that they are also more likely to have two jobs.

Unfortunately, the Spanish Labour Force Survey does not include measures of job satisfaction. Alternatively, I use the Spanish section of the European Household Panel (available for years 1994 to 2001) to understand differences by contract type related to satisfaction with several aspects of the job. More details about this dataset and the variables used are given in the Data Appendix, Section A2. In particular, the information in this dataset allows checking whether there are any differences in the degree of

\footnotetext{
${ }^{25}$ Note that I cannot work with this bigger sample in the main exercise since I can only define outcomes at age sixteen for children observed at exactly that moment -i.e. I cannot construct outcomes for children retrospectively.

${ }^{26}$ The first stage results are not shown, but the instrument is strong in this bigger sample. An increase of 1000 euros in the average subsidy increases the chances of observing the father with a permanent contract by about 1.8 percentage points (significant at the $1 \%$ level). Setting the confidence level to $5 \%$, the effective $\mathrm{F}$ test is equal to 42.579 . The test rejects the null for a weak instrument threshold of $\tau=5 \%$.
} 
satisfaction between workers with fixed-term and permanent contracts with respect to the following dimensions of their current job: earnings, job stability, type of job, number of hours worked, shift worked, environmental/work conditions and distance to the workplace. The degree of reported satisfaction can vary from 1 (not satisfied at all) to 6 (fully satisfied). ${ }^{27}$

Table 16 presents results with a structure similar to that in Table 15. Sample 1 is comparable to the main sample used while working with the Spanish LFS data. That is, columns 1 and 2 include observations with all (unique) fathers in the panel with a child turning sixteen throughout the panel (the year of observation selected is the year the child turns sixteen). Sample 2 used in columns 3 to 5 includes all fathers in the age range 34 to 65 (which is the same age range of fathers in the main sample using LFS data), independently of the age of the child. Controls in column 5 have been designed to be as close as possible as those used with LFS data. Overall, the results in column 5 show that, after controlling for a rich set of variables, fathers with permanent contracts are significantly more satisfied with several of the reported dimensions of their current job (earnings, job stability, type of job, distance to the workplace). Interestingly, in both samples, the item where fixed-term workers show a lower degree of satisfaction is satisfaction with their job stability. The average score for fixed-term workers is slightly below 3 (i.e. little satisfied); whereas workers with permanent contracts report an average job stability satisfaction of about 1.2 points more (after accounting for observable characteristics). Given the scale of scores (from 1 to 6 ) the magnitude of this difference is sizeable, especially when compared with the magnitude of the differences in all the other dimensions of job satisfaction. The 1.2 point estimate implies movements in the 6-step scale from 'little satisfied' to above 'pretty satisfied' when a worker with similar characteristics has a permanent, rather than a fixed-term contract.

Even if the set of controls used is rather rich, there could be other unobserved characteristics that are correlated with both contract type and measures of job satisfaction, that prevents this exercise from offering a causal interpretation. Unfortunately, the identification strategy used with the LFS data does not work as well in this context. Replicating the exercise with the household data, the first stage coefficient for the regional subsidies instrument has a magnitude of about 1.9 percentage points (very similar to the one obtained with LFS data), and is significant at the $1 \%$ level. However, it is less precisely estimated, and this makes the effective $\mathrm{F}$ stat to be low (8.157), making the instrument weak in this sample. ${ }^{28}$

Despite this shortcoming, the OLS evidence chimes well with recent work using UK and US data on typical versus atypical work arrangements. Datta (2019) shows that attributes typically associated

\footnotetext{
${ }^{27}$ In particular, the 6-step scale used in this survey stands for: (1) Not satisfied at all (No satisfecho en absoluto); (2) Minimally satisfied (Mínimamente satisfecho); (3) Little satisfied (Poco satisfecho); (4) Pretty satisfied (Bastante satisfecho); (5) Very satisfied (Muy satisfecho); and (6) Fully satisfied (Plenamente satisfecho).

${ }^{28}$ This can be due to a (smaller) sample size issue, but also to the fact that the period of data available only goes until 2001 , whereas regional subsidies that can potentially be exploited go from 1997 to 2004 .
} 
with traditional employee-employer relationships are by far the most valued. Interestingly, the findings show that, at the mean, individuals are willing to give up approximately $50 \%$ of their hourly wage for a permanent contract against a one month contract in the UK and US. These results highlight the value which individuals place on parameters associated with job security in both countries.

Work in social psychology allows to hypothesise about the potential intergenerational links between the pervasive effect of parental job insecurity on child outcomes. Barling et al. (1999) note that children as young as five years of age can develop clear perceptions of the world of work and parent's job insecurity; and understand concepts such as pay, labor disputes, unemployment and welfare. ${ }^{29}$ As a result, Barling et al. (1999) find that children's perceptions of their parent's job insecurity indirectly affect their grade performance through the effects of beliefs in an unjust world and negative mood. Similarly, Barling et al. (1998) find that children who watch their parents experiencing layoffs and insecurity, develop negative work beliefs that then predict their work-related attitudes.

Work by sociologists and social psychologists can also provide some explanations for the differential impact that the type of contract seems to have on school related outcomes of their children, depending on the gender of the parent. Even if the Spanish Household Panel data confirms that mothers on fixed-term contracts are similarly dissatisfied with certain aspects of their jobs, the results in Section 5 showed that the type of contract held by the mother does not seem to have an impact on any of the three school-related outcomes analysed here. Findings reported by social psychologists suggest that there are detrimental effects of job insecurity on financial anxiety for men but not for women (Lim and Sng, 2006). The recent work by Bartoll et al. (2018) finds evidence of a positive link between temporary employment and poor mental health both before and during the Great Recession in Spain, although only for men. Other literature in economics seems to confirm that men are more affected by negative labour market experiences. For instance, Kuhn et al. (2009) find that job loss significantly increases expenditures for antidepressants and related drugs, as well as hospitalisations due to mental health problems for men, but not for women. Eliason and Storrie (2009a) find that job loss produces a short-run increase in suicides and alcohol-related mortality for both sexes. However, overall mortality risk among men increased in the short run, while this did not happen for women. Eliason and Storrie (2009b) also find that job loss significantly increases the risk of hospitalisation due to alcohol-related conditions, among both men and women, but due to traffic accidents and self-harm among men only. Additionally, Rege et al. (2011) summarise theories of social identity and argue that "the variety of roles with which a woman identifies makes her more adaptable and equipped to handle job loss. In contrast, a man's identity is to a larger

\footnotetext{
${ }^{29}$ These authors summarise that the transmission of "information takes place in one of two ways, or both: Parents may verbally express to their children how they feel about their work, or they may communicate their feelings indirectly through mood or changes in behaviour".
} 
degree associated with his specific work. This suggests that, despite new employment opportunities, job loss can be detrimental for the man because a large part of his identity was connected to his specific job." The work by social psychologists and economists cited above, as well as the results presented in this paper, suggest that similar mechanisms could be behind the pervasive intergenerational consequences of job insecurity found for fathers (but not for mothers).

\section{Concluding Remarks}

Job insecurity has increased in most OECD countries in the aftermath of the Great Recession (OECD, 2016). While some degree of flexibility is needed for firms to adjust to the economic cycle, job insecurity can be harmful to affected workers. In particular, job-insecure fixed-term contracts have been shown to lead to lower wages, lower levels of job satisfaction, lower levels of physical and mental health and increased occupational mismatch, among other negative consequences. The evidence in this paper suggests that children of fathers with fixed-term contracts are also negatively affected.

As opposed to children whose fathers have fixed-term contracts, average marginal effects obtained from bivariate probit regressions indicate that students whose fathers hold a permanent contract the year they should graduate from compulsory education are, on average, about 7.8 percentage points more likely to graduate on time. They are also less likely to drop out of education at age sixteen by about 2.5 percentage points, and less likely to be classified as NEET at age sixteen by about 1.6 percentage points. These magnitudes are sizeable and represent, respectively, about 37\%, 19\% and $23 \%$ of the initial raw difference in these outcomes between individuals whose fathers have a permanent versus a fixed-term contract when children are aged sixteen. All these negative consequences make poor employment and earnings prospects more likely in the longer term.

I am able to provide insights of some of the relevant mechanisms, although more research is needed here. ${ }^{30}$ There is some indication in the data that fathers with fixed-term contracts might have a different amount of time available outside work hours to spend with their children. For instance, fathers with fixed-term contracts want to work more hours. Additionally, fathers on fixed-term contracts show significantly lower levels of job satisfaction in many aspects of their jobs; in particular with respect to satisfaction with job stability. According to the work by social psychologists, big differential effects in job satisfaction are likely to be felt at the household level since children are able to develop clear perceptions of the world of work and parent's job insecurity (Barling et al., 1999).

These findings have relevant policy implications for the evaluation of costs and benefits of employ-

\footnotetext{
${ }^{30}$ For instance, by using time use surveys, and as long as those include information on the type of contract held by parents.
} 
ment protection reforms that liberalise the use of fixed-term contracts. Considering only the consequences for workers misses the costs associated with the intergenerational impacts shown here, and potentially those existing for other members of the household. However, these cost-benefit calculations should also include any potential benefits that fixed-term contracts might have on reducing parental unemployment, and the potential intergenerational effect that this might entail for affected children.

All in all, given that a certain degree of flexibility is needed for firms to be able to make adjustments according to the economic cycle, it seems sensible to reinforce the welfare system by enacting policies that could potentially mitigate the cost of these adjustments in terms of the wellbeing of workers and their families. This is even more relevant in the current context of 'uberisation' of the economy and the appearance of zero-hour contracts, which are likely to lead to further increases in the levels of job insecurity in the future. 


\section{References}

Andrews, I., J. Stock, and L. Sun (2018). Weak instruments in IV regression: Theory and Practice. Working Paper.

Angrist, J. D. and J.-S. Pischke (2008). Mostly harmless econometrics: An empiricist's companion. Princeton University Press.

Barceló, C. and E. Villanueva (2016). The response of household wealth to the risk of job loss: Evidence from differences in severance payments. Labour Economics 39, 35-54.

Barling, J., K. E. Dupre, and C. G. Hepburn (1998). Effects of parents' job insecurity on children's work beliefs and attitudes. Journal of Applied Psychology 83(1), 112-118.

Barling, J., A. Zacharatos, and C. G. Hepburn (1999). Parents' job insecurity affects children's academic performance through cognitive difficulties. Journal of Applied Psychology 84(3), 437-444.

Bartoll, X., J. Gil, and R. Ramos (2018). Has the economic crisis worsened the work-related stress and mental health of temporary workers in Spain? IZA Discussion Paper No.11701.

Becker, G. S. (1993). A Treatise on the Family. Harvard University Press. Enlarged edition.

Bentolila, S., J. J. Dolado, and J. F. Jimeno (2008). Two-tier employment protection reforms: The spanish experience. CESifo DICE Report 4(2008), 49-56.

Blau, D. M. (1999). The effect of income on child development. Review of Economics and Statistics 81(2), 261-276.

Booth, A. L., M. Francesconi, and J. Frank (2002). Temporary jobs: stepping stones or dead ends? The Economic Journal 112(480), F189-F213.

Card, D. (1999). The causal effect of education on earnings. Handbook of Labor Economics 3, 18011863.

Chiburis, R. C., J. Das, and M. Lokshin (2012). A practical comparison of the bivariate probit and linear iv estimators. Economics Letters 117(3), 762-766.

Cook, P. J. and S. Kang (2016). Birthdays, schooling, and crime: regression-discontinuity analysis of school performance, delinquency, dropout, and crime initiation. American Economic Journal: Applied Economics 8(1), 33-57.

Datta, N. (2019). Willing to pay for security: A discrete choice experiment to analyse labour supply preferences. CEP Discussion Paper No. 1632. 
Dolado, J. J., C. García-Serrano, and J. F. Jimeno (2002). Drawing lessons from the boom of temporary jobs in Spain. The Economic Journal 112(480), F270-F295.

Duncan, G. J. and J. Brooks-Gunn (2000). Family poverty, welfare reform, and child development. Child Development 71(1), 188-196.

Eliason, M. and D. Storrie (2009a). Does job loss shorten life? Journal of Human Resources 44(2), $277-302$.

Eliason, M. and D. Storrie (2009b). Job loss is bad for your health. Swedish evidence on causespecific hospitalization following involuntary job loss. Social Science \& Medicine 68(8), 13961406.

Galdon-Sanchez, J. and M. Guell (2000). Let's go to court! Firing costs and dismissal conflicts. Working Paper No.444. Princeton University.

Garcia-Perez, I. J., I. Marinescu, and J. Vall-Castello (2018). Can fixed-term contracts put low skilled youth on a better career path? Evidence from Spain. The Economic Journal. In Press.

García-Pérez, J. I. and Y. F. Rebollo Sanz (2009). The use of permanent contracts across spanish regions: Do regional wage subsidies work? Investigaciones económicas 33(1), 97-130.

Green, F. (2015). Health effects of job insecurity. IZA World of labor 212.

Guadalupe, M. (2003). The hidden costs of fixed-term contracts: The impact on work accidents. Labour Economics 10, 338-358.

Güell, M. and B. Petrongolo (2007). How binding are legal limits? Transitions from temporary to permanent work in Spain. Labour Economics 14(2), 153-183.

Kuhn, A., R. Lalive, and J. Zweimüller (2009). The public health costs of job loss. Journal of Health Economics 28(6), 1099-1115.

Lim, V. and G. Leng Loo (2003). Effects of parental job insecurity and parenting behaviors on youth's self-efficacy and work attitudes. Journal of Vocational Behavior 63, 86-98.

Lim, V. K. and Q. S. Sng (2006). Does parental job insecurity matter? money anxiety, money motives, and work motivation. Journal of Applied Psychology 91(5), 1078.

Méndez, I. (2013). Promoting permanent employment: Lessons from Spain. SERIEs 4(2), 175-199.

Montiel Olea, J. L. and C. Pflueger (2013). A robust test for weak instruments. Journal of Business \& Economic Statistics 31(3), 358-369. 
Nikolova, M. and B. N. Nikolaev (2018). Family matters: The effects of parental unemployment in early childhood and adolescence on subjective well-being later in life. Journal of Economic Behavior \& Organization. In press.

OECD (2016). How good is your job? measuring and assessing job quality. OECD Publishing, Paris.

Pflueger, C. E. and S. Wang (2015). A robust test for weak instruments in stata. The Stata Journal 15(1), 216-225.

Pinger, P. (2016). Intergenerational effects of economic distress: Paternal unemployment and child secondary schooling decisions. Mimeo.

Rege, M., K. Telle, and M. Votruba (2011). Parental job loss and children's school performance. The Review of Economic Studies 78(4), 1462-1489.

Ruiz-Valenzuela, J. (2015). Job loss at home: children's school performance during the Great Recession in Spain. Centre for Economic Performance, Discussion Paper. No 1364; London School of Economics and Political Science.

Solon, G., S. J. Haider, and J. M. Wooldridge (2015). What are we weighting for? Journal of Human resources 50(2), 301-316.

Todd, P. E. and K. I. Wolpin (2003). On the specification and estimation of the production function for cognitive achievement. The Economic Journal 113(485), F3-F33. 


\section{Tables and Figures}

Figure 1: Fixed-Term employment rates in Spain (\%)

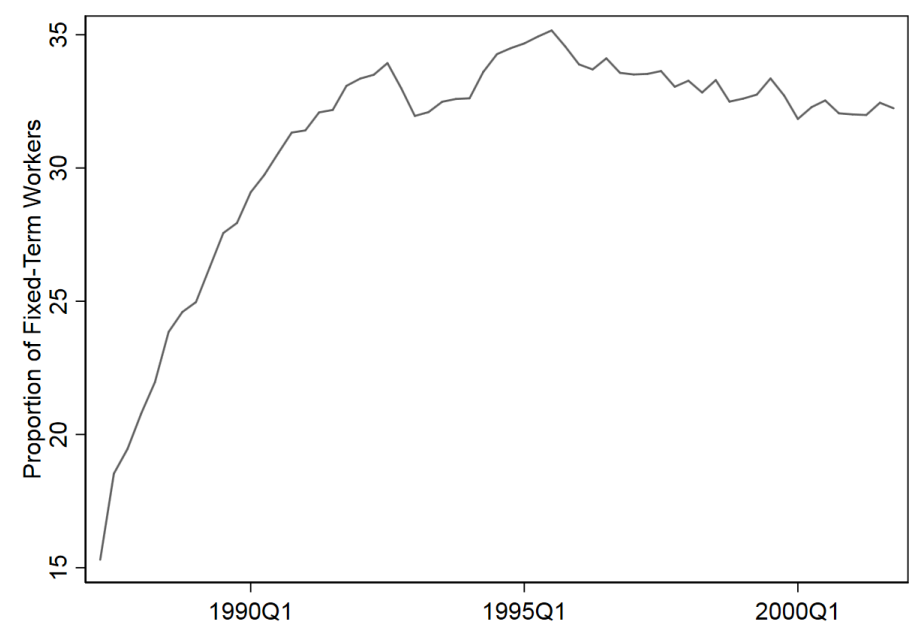

Source: Spanish National Institute of Statistics. The first data point starts in the second quarter of 1987. The series shows total employment under fixed-term contracts over total employment. 
Figure 2: Regional subsidies from Barceló and Villanueva (2016)

Subsidies for conversion of fixed-term contracts into open-ended ones, by region and year.

\begin{tabular}{|c|c|c|c|c|}
\hline Region/year & 1997 & 1998 & 1999 & 2000 \\
\hline 1. Andalucia & \multicolumn{4}{|c|}{ Between 1997 and 2000: 4200 if age $<30,3000$ if female $>30,2400$ if male $>30$} \\
\hline \multirow{3}{*}{ 2. Aragon } & \multirow{3}{*}{ None } & 4200 if female or age $>45$ & 5160 if female or age $>45$ & 5160 if female or age $>45$ \\
\hline & & 3000 if male $41 \leq$ age $\leq 44$ & 4500 if $41 \leq$ age $\leq 44$ & 4500 if $41 \leq$ age $\leq 44$ \\
\hline & & \multirow{3}{*}{4500 for all } & 3600 if male age $<30$ & 3600 if male age $<46$ \\
\hline \multirow[t]{2}{*}{ 3. Asturias } & \multirow[t]{2}{*}{4500 for all } & & \multirow[t]{2}{*}{ None } & 4200 if female or age $\geq 46$ \\
\hline & & & & $\begin{array}{l}3600 \text { otherwise } \\
1652.78 \text { if female }\end{array}$ \\
\hline \multirow{2}{*}{ 5. Canarias } & \multirow{2}{*}{ None } & \multirow{2}{*}{3600 if female or age $\leq 25$} & $\begin{array}{l}\text { None } \\
3600 \text { if female or age } \leq 25\end{array}$ & \multirow{2}{*}{ None } \\
\hline & & & $\begin{array}{l}3600 \text { if female or age } \leq 25 \\
3000 \text { otherwise }\end{array}$ & \\
\hline \multirow[t]{3}{*}{ 6. Cantabria } & \multirow[t]{3}{*}{ None } & 3900 if female or age $\leq 30$ & \multirow{3}{*}{ None } & 5408 if age $\geq 46$ \\
\hline & & 3300 if male $30<$ age $\leq 40$ & & 3606 if age $\leq 30$ \\
\hline & & 3600 if male age $\geq 41$ & & 2163 otherwise \\
\hline \multirow[t]{3}{*}{ 7. Castilla-Leon } & \multirow[t]{3}{*}{ None } & 5112 if female or age $<30$ & 5115 if age $<30$ & 4507.59 if age $<30$ \\
\hline & & 3300 rest of males & 3900 if female age $\geq 30$ & 3305.57 if female age $\geq 30$ \\
\hline & & & 1800 if male age $\geq 41$ & 1803 if male age $\geq 41$ \\
\hline \multirow[t]{2}{*}{ 8. Castilla-La Mancha } & \multirow[t]{2}{*}{ None } & 3600 if females & \multirow[t]{2}{*}{ None } & 3600 if female \\
\hline & & 3000 if age $<30$ & & 3000 if age $>45$ or age $<30$ \\
\hline 10. Valencia & None & $30 \%$ of payroll tax & $30 \%$ of payroll tax & $30 \%$ of payroll tax \\
\hline \multirow[t]{3}{*}{ 11. Extremadura } & $10,655.94$ if age $<45$ & 10,100 if age $\leq 30$ & $14,027.62$ if age $>46$ & 5217.076 if female age $>46$ \\
\hline & \multirow{2}{*}{$13,402.57$ if age $>45$} & 11,180 if age $>30$ and age $\leq 40$ & \multirow{2}{*}{$11,178.83$ if age $<45$} & \multirow{2}{*}{4296.416 if male age $>46$} \\
\hline & & 14,027 if age $>40$ & & \\
\hline \multirow[t]{2}{*}{ 12. Galicia } & \multirow[t]{2}{*}{ None } & 4200 euro if female or age $<30$ & 1800 for males & 1800 for males \\
\hline & & 3000 if age $>45$ & 2400 for females & 2400 for females \\
\hline \multirow{2}{*}{ 13. Madrid } & \multirow[t]{2}{*}{ None } & 6000 euro if female & 7800 if female & 9000 if female \\
\hline & & 6000 euro if age $<30$ or age $>40$ & 7800 if age $<25$ or age $>40$ & 6600 if age $<25$ or age $>40$ \\
\hline \multirow[t]{2}{*}{ 14. Murcia } & \multirow[t]{2}{*}{ None } & \multirow[t]{2}{*}{ None } & \multirow[t]{2}{*}{ None } & 2100 if age $<30$ \\
\hline & & & & 1800 for the rest \\
\hline 16. Basque country & None & 7512 for all & 7512 for all & 7512 for all \\
\hline 17. Rioja & None & 4500 for all & 4491 for all & 6011 for all \\
\hline
\end{tabular}

Note: The number associated with each Spanish region corresponds with the code given to the region by the Spanish Statistical Office (in Spanish, Instituto Nacional de Estadística, INE). Catalonia (region 9) and Navarra (region 15) have not implemented any subsidies to job contract conversions during the period 1997-2004.

\begin{tabular}{|c|c|c|c|c|}
\hline Region/year & 2001 & 2002 & 2003 & 2004 \\
\hline 1. Andalucia & $\begin{array}{l}4200 \text { if age }<30 \\
3000 \text { if females }>30 \\
2400 \text { if males }>30\end{array}$ & $\begin{array}{l}6012 \text { for females or age }<30 \\
3607 \text { if male age }>40\end{array}$ & None & None \\
\hline 2. Aragon & $\begin{array}{l}5160 \text { if female or age }>45 \\
4500 \text { if age } \geq 41 \\
3600 \text { if male age }<30\end{array}$ & $\begin{array}{l}4500 \text { if female } \\
4125 \text { if age }<30 \text { or age } \geq 41\end{array}$ & $\begin{array}{l}4500 \text { if female } \\
4125 \text { if age }<30 \text { or age } \geq 41\end{array}$ & 3750 if male, 7250 if female \\
\hline 3. Asturias & $\begin{array}{l}4200 \text { if female or age } \geq 46 \\
3600 \text { otherwise }\end{array}$ & $\begin{array}{l}4200 \text { if female of age }>46 \\
3600 \text { otherwise }\end{array}$ & $\begin{array}{l}4200 \text { if female of age }>46 \\
3600 \text { otherwise }\end{array}$ & None \\
\hline 4. Baleares & 1652.78 for females & 1800 for females & 4808 for females & 4808 for females \\
\hline 5. Canarias & None & None & None & None \\
\hline 6. Cantabria & $\begin{array}{l}4808 \text { for females } \\
3005 \text { if male age } \leq 30 \\
4207 \text { if age }>45,1803 \text { otherwise }\end{array}$ & Same as previous year & Same as previous year & Same as previous year \\
\hline 7. Castilla-Leon & $\begin{array}{l}4507.59 \text { if age }<30 \\
3305.57 \text { if female age }>31 \\
1803 \text { if male age }>41\end{array}$ & Same as previous year & Same as previous year & Same as previous year \\
\hline 8. Castilla-La Mancha & $\begin{array}{l}3600 \text { if female } \\
3000 \text { if age }>45 \text { or age }<30\end{array}$ & Same as previous year & Same as previous year & None \\
\hline 10. Valencia & 4808.1 for all & 1800 for females & $\begin{array}{l}2000 \text { for females } \\
1500 \text { for the rest }\end{array}$ & $\begin{array}{l}4000 \text { if female } \\
2000 \text { if age }<30,1500 \text { otherwise }\end{array}$ \\
\hline 11. Extremadura & $\begin{array}{l}5410.086 \text { if female }>45 \\
4455.365 \text { if male }>45 \\
2386.802 \text { otherwise }\end{array}$ & 6010 for all & None & None \\
\hline 12. Galicia & $\begin{array}{l}1800 \text { for males } \\
2400 \text { for females }\end{array}$ & $\begin{array}{l}1800 \text { for males } \\
2400 \text { for females }\end{array}$ & $\begin{array}{l}1800 \text { for males } \\
2400 \text { if females }\end{array}$ & $\begin{array}{l}1800 \text { for males } \\
2400 \text { for females }\end{array}$ \\
\hline 13. Madrid & $\begin{array}{l}12,000 \text { if above } 45 \text { (males) } \\
12,000 \text { if above } 40 \text { (females) } \\
10,800 \text { for the rest }\end{array}$ & 12,000 for all & $\begin{array}{l}9000 \text { if age } \leq 45 \\
12,000 \text { if above } 45\end{array}$ & 3000 euro, all \\
\hline 14. Murcia & 4800 for all & 4800 for all & $\begin{array}{l}4800 \text { if age above } 30 \\
5400 \text { if female or age } 30 \text { or below }\end{array}$ & 2400 for all \\
\hline 16. Basque country & 7512 for all & 7512 for all & 7512 for all & 6000 for males, 7500 for females \\
\hline
\end{tabular}

Note: The number associated with each Spanish region corresponds with the code given to the region by the Spanish Statistical Office (in Spanish, Instituto Nacional de Estadistica, INE). Catalonia (region 9) and Navarra (region 15) have not implemented any subsidies to job contract conversions during the period 1997-2004.

Source: Table taken from Barceló and Villanueva (2016). 
Table 1: Descriptive statistics: Outcomes at Age 16 by Father's Contract Type

\begin{tabular}{lcccc}
\hline & $(1)$ & $(2)$ & $(3)$ \\
& Permanent Contract & Fixed-Term Contract & All \\
\hline On time compulsory schooling graduation & 0.616 & 0.408 & 0.577 \\
& $(0.487)$ & $(0.492)$ & $(0.494)$ \\
Not in education & & & \\
& 0.060 & 0.193 & $(0.278)$ \\
Not in education, employment or training & $(0.237)$ & $(0.395)$ & 0.048 \\
& & & $(0.214)$ \\
\hline Observations & $(0.184)$ & $(0.306)$ & 4737 \\
\hline
\end{tabular}

Note: Own calculations based on the pooled Spanish Labour Force Survey (third quarter of 2000, 2001, 2002, 2003 and 2004). Details on variable construction can be found in the Data Appendix. First line corresponds to the mean for each variable. Standard deviations in parentheses. All variables measured in the fourth quarter of the year in which the individual should finish compulsory education if she is to finish on time. 


\begin{tabular}{|c|c|c|c|}
\hline & (1) & (2) & (3) \\
\hline & Permanent Contract (PC) & Fixed-Term Contract (FTC) & All \\
\hline \multicolumn{4}{|c|}{ Panel A. Father's personal characteristics: } \\
\hline \multirow[t]{2}{*}{ Age at hire } & 46.64 & 45.15 & 46.36 \\
\hline & $(5.121)$ & $(5.392)$ & $(5.204)$ \\
\hline \multirow[t]{2}{*}{ Post-compulsory education } & 0.403 & 0.0978 & 0.346 \\
\hline & $(0.491)$ & $(0.297)$ & $(0.476)$ \\
\hline \multirow[t]{2}{*}{ Married } & 0.995 & 0.984 & 0.993 \\
\hline & $(0.0736)$ & $(0.125)$ & $(0.0856)$ \\
\hline \multirow[t]{2}{*}{ Non-Spanish national } & 0.025 & 0.063 & 0.032 \\
\hline & $(0.157)$ & $(0.242)$ & $(0.177)$ \\
\hline \multicolumn{4}{|l|}{ Panel B. Father's job characteristics: } \\
\hline \multirow[t]{2}{*}{ Years at current job } & 17.39 & 2.105 & 14.56 \\
\hline & $(9.391)$ & $(3.781)$ & (10.48) \\
\hline \multirow[t]{2}{*}{ Firm has more than 50 employees } & 0.598 & 0.507 & 0.581 \\
\hline & $(0.490)$ & $(0.500)$ & $(0.493)$ \\
\hline \multirow[t]{2}{*}{ Works part-time } & 0.006 & 0.014 & 0.007 \\
\hline & $(0.0770)$ & $(0.116)$ & $(0.0856)$ \\
\hline \multirow[t]{2}{*}{ Works in the public sector } & 0.269 & 0.0865 & 0.235 \\
\hline & $(0.443)$ & $(0.281)$ & $(0.424)$ \\
\hline \multicolumn{4}{|c|}{ Panel C. Other household and children's characteristics: } \\
\hline \multirow[t]{2}{*}{ Household size } & 4.388 & 4.573 & 4.422 \\
\hline & $(0.978)$ & $(1.084)$ & $(1.001)$ \\
\hline \multirow[t]{2}{*}{ Whether mother works } & 0.468 & 0.414 & 0.458 \\
\hline & $(0.499)$ & $(0.493)$ & $(0.498)$ \\
\hline \multirow[t]{2}{*}{ Female } & 0.481 & 0.463 & 0.478 \\
\hline & $(0.500)$ & $(0.499)$ & $(0.500)$ \\
\hline \multirow[t]{2}{*}{ Month of birth } & 5.836 & 5.652 & 5.802 \\
\hline & $(3.068)$ & $(3.138)$ & $(3.082)$ \\
\hline \multirow[t]{2}{*}{ Regional subsidies (age range students) } & 2.836 & 2.264 & 2.730 \\
\hline & $(2.789)$ & $(2.447)$ & $(2.738)$ \\
\hline \multicolumn{4}{|c|}{ Panel D. Instrument: Amount of regional subsidies: } \\
\hline Regional subsidies father (in '000s) & 0.357 & 1.510 & 0.570 \\
\hline (amount father was eligible for) & $(1.368)$ & $(2.080)$ & $(1.590)$ \\
\hline Observations & 3858 & 879 & 4737 \\
\hline
\end{tabular}


Basic specification:

Regional dummies (at the NUTS-2 level)

Age dummies father (at hiring)

Third order polynomial in father's tenure

Father started contract after 1997

Year dummies (year of observation)

\section{Extra controls:}

Father's maximum education reached dummies

Sector of the firm

Additional student characteristics:

Gender

Quarter of birth

Father's Nationality (Not Spanish=1)

Regional unemployment rate, age range student (year of observation)

Regional subsidies, age range student (year of observation)

Note: Variable construction and sources can be found in the Data Appendix.

Table 4: Intention to Treat Estimates: Impact of Regional Subsidies Available to Fathers

\begin{tabular}{lccc}
\hline & $(1)$ & $(2)$ & $(3)$ \\
\hline \multicolumn{2}{l}{ Panel A. First stage: Permanent Contract Equation } & & \\
Mean subsidy in first 2 years of tenure & $0.021^{* * *}$ & $0.022^{* * *}$ & $0.022^{* * *}$ \\
& $(0.005)$ & $(0.005)$ & $(0.005)$ \\
Mean Outcome (share permanent contracts) & & 0.814 & 18.038 \\
Effective F statistic & 14.655 & 17.938 & \\
Critical values (\% Worst Case Bias: $\tau=10 \%)$ & & 23.109 & 15.062 \\
Critical values (\% Worst Case Bias: $\tau=20 \%)$ & & \\
Panel B. Reduced Form: Graduating on time Equation & $0.011^{* *}$ & $0.010^{*}$ & $0.011^{* *}$ \\
Mean subsidy in first 2 years of tenure & $(0.006)$ & $(0.005)$ & $(0.005)$ \\
& & 0.408 & \\
\hline
\end{tabular}

Note: Own calculations based on the pooled Spanish Labour Force Survey (third quarter of 2000 to 2004). Linear probability model estimates. Clustered robust SE in parentheses (clustered at the regional subsidy cell level). Variables included in the different specifications are reported in Table 3. *, **, *** denote significance at the $10 \%, 5 \%$ and $1 \%$ levels. Sample includes those students whose fathers have a permanent or fixed-term contract in the year of observation. FTC: fathers with Fixed-Term contracts. Effective F statistics and critical values shown are for the Montiel Olea-Pflueger robust weak instrument test with confidence level of $\alpha=5 \%$ and obtained with the weakivtest command in Stata (Pflueger and Wang, 2015). 
Table 5: Impact of Regional Subsidies Available to Mothers

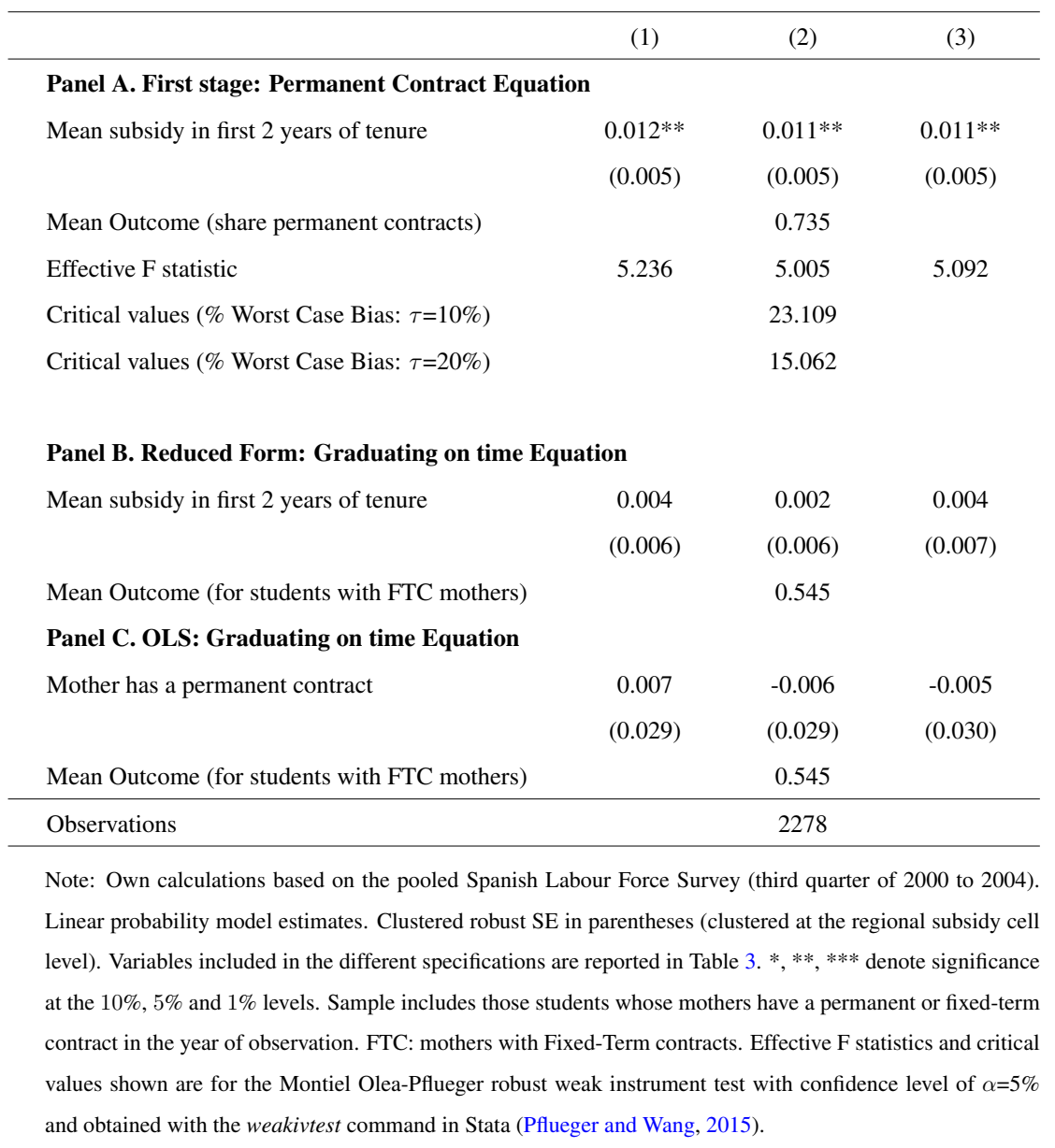


Table 6: Intention to Treat Estimates: Robustness checks including second order interactions

\begin{tabular}{|c|c|c|c|c|}
\hline & (1) & (2) & (3) & (4) \\
\hline \multicolumn{5}{|c|}{ Panel A. First stage: Permanent Contract Equation } \\
\hline \multirow[t]{2}{*}{ Mean subsidy in first 2 years of tenure } & $0.022 * * *$ & $0.023 * * *$ & $0.017 * * *$ & $0.015 * *$ \\
\hline & $(0.005)$ & $(0.006)$ & $(0.006)$ & $(0.006)$ \\
\hline Mean Outcome (share permanent contracts) & \multicolumn{4}{|c|}{0.814} \\
\hline Effective F statistic & 18.038 & 15.500 & 8.557 & 6.133 \\
\hline Critical values ( $\%$ Worst Case Bias: $\tau=10 \%$ ) & \multicolumn{4}{|c|}{23.109} \\
\hline Critical values ( $\%$ Worst Case Bias: $\tau=20 \%$ ) & \multicolumn{4}{|c|}{15.062} \\
\hline \multicolumn{5}{|c|}{ Panel B. Reduced Form: Graduating on time Equation } \\
\hline \multirow[t]{2}{*}{ Mean subsidy in first 2 years of tenure } & $0.011 * *$ & $0.014 * *$ & $0.013^{*}$ & $0.016^{*}$ \\
\hline & $(0.005)$ & $(0.007)$ & $(0.007)$ & $(0.008)$ \\
\hline Mean Outcome (for students with FTC fathers) & \multicolumn{4}{|c|}{0.408} \\
\hline \multicolumn{5}{|l|}{ Second order interactions } \\
\hline Region $\mathrm{x}$ Age at hire & & $\checkmark$ & $\checkmark$ & $\checkmark$ \\
\hline Age at hire $\mathrm{x}$ tenure & & & $\checkmark$ & $\checkmark$ \\
\hline Region $\mathrm{x}$ tenure & & & & $\checkmark$ \\
\hline Observations & \multicolumn{4}{|c|}{4737} \\
\hline
\end{tabular}

Note: Own calculations based on the pooled Spanish Labour Force Survey (third quarter of 2000 to 2004). Linear probability model estimates. Clustered robust SE in parentheses (clustered at the regional subsidy cell level). Variables included in the different specifications are reported in Table 3, Column 3. *,**, *** denote significance at the $10 \%, 5 \%$ and $1 \%$ levels. Sample includes those students whose fathers have a permanent or fixed-term contract in the year of observation. FTC: fathers with FixedTerm contracts. Effective F statistics and critical values shown are for the Montiel Olea-Pflueger robust weak instrument test with confidence level of $\alpha=5 \%$ and obtained with the weakivtest command in Stata (Pflueger and Wang, 2015). 
Table 7: First Stage: Permanent Contract Equation (Father) - Robustness Checks

\begin{tabular}{|c|c|c|c|c|c|c|c|c|}
\hline & (1) & (2) & (3) & (4) & (5) & (6) & (7) & (8) \\
\hline Mean subsidy in first 2 years of tenure: Father & $(0.005)$ & $(0.005)$ & $(0.005)$ & $(0.009)$ & $(0.005)$ & $(0.005)$ & $(0.007)$ & \\
\hline Mean subsidy in first 2 years of tenure: Mother & & & $(0.003)$ & $(0.003)$ & & & & \\
\hline Eligibility for subsidies first 2 years of tenure: Father & & & & & & & & $0.083 * * *$ \\
\hline Mean Outcome (share permanent contracts) & 0.814 & 0.814 & 0.814 & 0.835 & 0.814 & 0.778 & 0.816 & 0.814 \\
\hline Effective F statistic & 18.038 & 2.902 & 18.144 & 7.849 & 18.004 & 20.456 & 26.901 & 13.364 \\
\hline Critical values ( $\%$ Worst Case Bias: $\tau=10 \%$ ) & \multicolumn{8}{|c|}{23.109} \\
\hline Critical values ( $\%$ Worst Case Bias: $\tau=20 \%$ ) & \multicolumn{8}{|c|}{15.062} \\
\hline Subsidies mother (0 for unemployed) & & & $\checkmark$ & & & & & \\
\hline Subsidies mother (excluding unemployed) & & & & $\checkmark$ & & & & \\
\hline Dummy for father entering labour market after 1984 & & & & & $\checkmark$ & & & \\
\hline Excluding public sector workers & & & & & & $\checkmark$ & & \\
\hline Using survey weights & & & & & & & $\checkmark$ & \\
\hline Dummy instrument based on eligibility (rather than amount) & & & & & & & & $\checkmark$ \\
\hline
\end{tabular}

Note: Own calculations based on the pooled Spanish Labour Force Survey (third quarter of 2000 to 2004). Linear probability model estimates in all columns. Clustered robust $\mathrm{SE}$ in parentheses (clustered at the regional subsidy cell level). Variables included shown in spec. 3, Table 3 (unless otherwise stated in the robustness checks). *, **, *** denote significance at the $10 \%, 5 \%$ and $1 \%$ levels. Effective $\mathrm{F}$ statistics and critical values shown are for the Montiel Olea-Pflueger robust weak instrument test with confidence level of $\alpha=5 \%$ and obtained with the weakivtest command in Stata (Pflueger and Wang, 2015). 
Table 8: Reduced Form Equations (Father) - Robustness Checks

\begin{tabular}{|c|c|c|c|c|c|c|c|c|}
\hline & (1) & (2) & (3) & (4) & (5) & (6) & (7) & $\left(8^{+}\right)$ \\
\hline \multicolumn{9}{|l|}{ Panel A. Reduced Form: Graduating on time Equation } \\
\hline \multirow[t]{2}{*}{ Mean subsidy in first 2 years of tenure: Father } & $0.011 * *$ & 0.006 & $0.011 * *$ & 0.007 & $0.011 * *$ & $0.015^{* *}$ & $0.017 * * *$ & $0.065^{* *}$ \\
\hline & $(0.005)$ & $(0.006)$ & $(0.005)$ & $(0.009)$ & $(0.005)$ & $(0.006)$ & $(0.006)$ & $(0.027)$ \\
\hline Share graduation on time (FTC fathers) & 0.408 & 0.408 & 0.408 & 0.427 & 0.408 & 0.402 & 0.408 & 0.408 \\
\hline Observations & 4737 & 4737 & 4737 & 1915 & 4737 & 3625 & 4737 & 4737 \\
\hline Preferred specification (controls as in Table 3, Col.3) & $\checkmark$ & & & & & & & \\
\hline Year of hire fixed effects & & $\checkmark$ & & & & & & \\
\hline Subsidies mother ( 0 for unemployed) & & & $\checkmark$ & & & & & \\
\hline Subsidies mother (excluding unemployed) & & & & $\checkmark$ & & & & \\
\hline Dummy for father entering labour market after 1984 & & & & & $\checkmark$ & & & \\
\hline Excluding public sector workers & & & & & & $\checkmark$ & & \\
\hline Using survey weights & & & & & & & $\checkmark$ & \\
\hline Dummy instrument based on eligibility (rather than amount) & & & & & & & & $\checkmark$ \\
\hline
\end{tabular}

Note: Own calculations based on the pooled Spanish Labour Force Survey (third quarter of 2000 to 2004). Linear probability model estimates in all columns. Clustered robust SE in parentheses (clustered at the regional subsidy cell level). Variables included shown in spec. 3, Table 3 (unless otherwise stated in the robustness checks). + Results in the last column show the impact of the dummy based on eligibility for subsidies in the first 2 years of tenure. *, **, *** denote significance at the $10 \%$, $5 \%$ and $1 \%$ levels. 
Table 12: Counting and characterising compliers

\begin{tabular}{|c|c|c|}
\hline \multicolumn{3}{|l|}{ Panel A. Probabilities of compliance } \\
\hline Proportion treated (i.e. fathers with a PC) & \multicolumn{2}{|r|}{0.814} \\
\hline Size of the complier group (overall first stage) & \multicolumn{2}{|r|}{0.083} \\
\hline Size of the complier population (relative to the treated population) & \multicolumn{2}{|r|}{0.018} \\
\hline Panel B. Complier's characteristics & Subgroup first stage & Complier's likelihood ratio \\
\hline Father has post-compulsory education & $0.126(0.051)$ & 1.524 \\
\hline Married father & $0.083(0.023)$ & 1.001 \\
\hline Father is Spanish & $0.084(0.023)$ & 1.017 \\
\hline
\end{tabular}

Table 13: Other Outcomes: Impact of Father's Contract Type

\begin{tabular}{lcc}
\hline & $(1)$ & $\begin{array}{c}(2) \\
\text { BIPROBIT }\end{array}$ \\
\hline Equation: Not in Education at 16 & OLS & $-0.025^{*}$ \\
Father has a PERMANENT contract & $-0.047^{* * *}$ & $(0.014)$ \\
P-val LRtest of rho=0 & $-0.018)$ & 0.838 \\
Mean Outcome (for students with FTC fathers) & 0.193 & \\
Equation: Not in Education, Employment or Training at 16 & $-0.029 * *$ & $(0.012)$ \\
Father has a PERMANENT contract & $(0.015)$ & 0.848 \\
P-val LRtest of rho=0 & - & 0.105 \\
Mean Outcome (for students with FTC fathers) & & \\
\hline
\end{tabular}

Note: Own calculations based on the pooled Spanish Labour Force Survey (third quarter of 2000 to 2004). Linear probability model estimates in Column 1; average marginal effects from bivariate probit regressions in Column 2 (for the probability $\operatorname{Pr}($ Not in Education at 16=1) and $\operatorname{Pr}($ Not in Education, Employment or Training at 16=1), respectively). Each cell shows estimates from a different regression. Clustered robust SE in parentheses (clustered at the regional subsidy cell level). Delta method standard errors obtained after bivariate probit regressions with the Stata margins command. Variables included as in Table 3, Column 3. *,**,*** denote significance at the $10 \%, 5 \%$ and $1 \%$ levels. Sample includes those students whose fathers have a permanent or fixed-term contract in the year of observation (4737 observations). FTC fathers: fathers with Fixed-Term contracts. 
Table 15: Potential mechanisms: differences between fathers with fixed-term and permanent contracts in the Spanish Labour Force Survey

\begin{tabular}{|c|c|c|c|c|c|c|}
\hline & (1) & (2) & (3) & (4) & (5) & (6) \\
\hline & Mean FTC & Raw difference & Mean FTC & Raw difference & Diff incl. & 2SLS/BIPROBIT \\
\hline & Sample & PC, Sample & All (16-20) & PC, All (16-20) & controls, All (16-20) & All (16-20) \\
\hline \multirow[t]{2}{*}{ Normal weekly hours worked } & 41.209 & -0.337 & 40.923 & $-0.247 * * *$ & $0.683 * * *$ & -0.824 \\
\hline & & $(0.215)$ & & $(0.089)$ & $(0.188)$ & $(2.135)$ \\
\hline \multirow[t]{2}{*}{ Deviation (normal-worked) hours } & 4.501 & -0.550 & 4.607 & $-0.470 * * *$ & -0.216 & -3.236 \\
\hline & & $(0.375)$ & & $(0.159)$ & $(0.308)$ & $(3.523)$ \\
\hline \multirow[t]{2}{*}{ Wants to work more hours } & 0.025 & $-0.015^{* * *}$ & 0.022 & $-0.015^{* * *}$ & $-0.011 * * *$ & $-0.009 * *$ \\
\hline & & $(0.005)$ & & $(0.002)$ & $(0.004)$ & $(0.004)$ \\
\hline \multirow[t]{2}{*}{ Has another job } & 0.030 & 0.002 & 0.028 & 0.002 & -0.005 & $0.020^{*}$ \\
\hline & & $(0.006)$ & & $(0.003)$ & $(0.006)$ & $(0.011)$ \\
\hline \multirow[t]{2}{*}{ Looking for another job } & 0.034 & $-0.030 * * *$ & 0.038 & $-0.034 * * *$ & $-0.026 * * *$ & 0.012 \\
\hline & & $(0.006)$ & & $(0.003)$ & $(0.004)$ & $(0.009)$ \\
\hline
\end{tabular}

Note: Own calculations based on the pooled Spanish Labour Force Survey (third quarter of 2000 to 2004). FTC: Father with a Fixed-Term contract in the year of observation. PC: Father with a permanent contract in the year of observation. Columns 1 and 3 show means for FTC fathers in the working sample; and for all the FTC fathers of children aged 16 to 20, respectively. Columns 2 and 4 show raw differences between fathers with FTC and PC. Robust standard errors in parentheses in Columns 2 and 4 are obtained from a regression of each variable on a dummy indicating whether the father has a PC. Column 5 shows differences after accounting for the variables in Table 3, Column 3 (except those that refer exclusively to children's characteristics). Column 6 shows the main equation using 2SLS for the first two variables, and average marginal effects from bivariate probit estimates for the probability $\operatorname{Pr}(\operatorname{Variable}=1)$ for the last 3 variables. The effective F statistic for the first stage in Column 6 (linear setting) is 40.747 (and the critical value for $\tau=5 \%$ is 37.418 ). The P-value for the LRtest of rho=0 for the last 3 variables in column 6 is 0.576, 0.053 and 0.001, respectively. Clustered robust SE in parentheses (clustered at the regional subsidy cell level) in Columns 5 and 6. Delta method standard errors obtained after bivariate probit regressions with the Stata margins command for the last 3 variables in column $6 . *$, **, *** denote significance at the $10 \%, 5 \%$ and $1 \%$ levels. There are 879 (3858) fathers with a FTC (PC) in the working sample. There are 5039 (23933) fathers with a FTC (PC) in the sample of children aged 16 to 20 . 
Table 16: Potential mechanisms: differences between fathers with fixed-term and permanent contracts in terms of satisfaction in the current job

\begin{tabular}{cccccc}
\hline & $(1)$ & $(2)$ & $(4)$ & $(5)$ & $(6)$ \\
Mean FTC & Raw difference & Mean FTC & Raw difference & Diff incl. \\
Sample1 & PC, Sample1 & Sample2 & PC, Sample2 & controls, Sample2 \\
\hline
\end{tabular}

Degree of Satisfaction with different dimensions of the current job (from 1(not satisfied) to 6 (fully satisfied)):

\begin{tabular}{|c|c|c|c|c|c|}
\hline \multirow[t]{2}{*}{ Earnings } & 2.805 & $0.538 * * *$ & 2.932 & $0.498 * * *$ & $0.198 * *$ \\
\hline & & $(0.127)$ & & $(0.065)$ & $(0.097)$ \\
\hline Observations & 118 & 602 & 468 & 2325 & 2251 \\
\hline \multirow[t]{2}{*}{ Job Stability } & 2.857 & $1.930 * * *$ & 2.962 & $1.788 * * *$ & $1.253^{* * *}$ \\
\hline & & $(0.135)$ & & $(0.071)$ & $(0.107)$ \\
\hline Observations & 119 & 602 & 470 & 2326 & 2253 \\
\hline \multirow[t]{2}{*}{ Type of Job } & 4.143 & $0.384 * * *$ & 3.962 & $0.542 * * *$ & $0.395 * * *$ \\
\hline & & $(0.128)$ & & $(0.068)$ & $(0.100)$ \\
\hline Observations & 119 & 603 & 470 & 2327 & 2253 \\
\hline \multirow[t]{2}{*}{ Number of hours worked } & 3.798 & 0.131 & 3.600 & $0.344 * * *$ & -0.011 \\
\hline & & $(0.131)$ & & $(0.071)$ & $(0.102)$ \\
\hline Observations & 119 & 603 & 470 & 2325 & 2251 \\
\hline \multirow[t]{2}{*}{ Shift } & 4.176 & 0.076 & 4.026 & $0.221 * * *$ & -0.087 \\
\hline & & $(0.135)$ & & $(0.068)$ & $(0.097)$ \\
\hline Observations & 119 & 603 & 468 & 2320 & 2246 \\
\hline \multirow[t]{2}{*}{ Work/Environmental Conditions } & 3.966 & $0.278 * *$ & 3.853 & $0.339 * * *$ & 0.161 \\
\hline & & $(0.138)$ & & $(0.071)$ & $(0.098)$ \\
\hline Observations & 117 & 601 & 469 & 2324 & 2250 \\
\hline \multirow[t]{2}{*}{ Distance to Workplace } & 3.832 & $0.492 * * *$ & 3.702 & $0.549 * * *$ & $0.215^{*}$ \\
\hline & & $(0.154)$ & & $(0.076)$ & $(0.112)$ \\
\hline Observations & 119 & 603 & 470 & 2327 & 2253 \\
\hline
\end{tabular}

Note: Own calculations based on the Spanish Household Panel. Sample 1 includes all (unique) fathers in the panel with a child turning 16 throughout the panel (year of observation selected is the year the child turns 16). Sample 2 includes all fathers in the age range 34 to 65 , with children living at home, independently of the age of the child (year of observation selected in the panel is the last year in the sample). FTC: Father with a Fixed-Term contract in the year of observation. PC: Father with a permanent contract in the year of observation. Columns 1 and 3 show means for (unique) fathers with fixed-term contracts in Sample1 and Sample 2, respectively. The number of observations for Columns 1 and 3 correspond to the number of fathers with FTC in each sample with non-missing data for the variable of interest. Columns 2 and 4 show raw differences between fathers with FTC and PC, with robust standard errors in parentheses obtained from a regression of each variable on a dummy indicating whether the father has a PC. Column 5 shows differences after accounting for the variables in Table 3, Column 3 (except those that refer exclusively to children's characteristics), with clustered robust SE in parentheses (clustered at the regional subsidy cell level). The number of observations in Columns 2, 4 and 5 correspond to the number of fathers included in the regressions. All outcomes can take values from 1 (not satisfied) to 6 (fully satisfied). *,**,*** denote significance at the $10 \%, 5 \%$ and $1 \%$ levels. 


\section{Appendix A. Data Appendix}

\section{A1 The Spanish Labour Force Survey}

The Spanish Labour Force Survey (Encuesta de Población Activa, or Economically Active Population Survey) is a representative household survey conducted by the Spanish National Institute of Statistics. The survey has been in place since 1964 and interviews around 65000 families every quarter. All the members aged 16 or more when the survey takes place respond to the individual questionnaires. There are two versions of the data: longitudinal and cross-section. In the longitudinal version households can be tracked during 6 consecutive quarters, but the information corresponding to the age of individuals is aggregated in 5-year intervals. In the cross-section version households cannot be tracked, but there is information on the birth date of individuals. Knowledge of the individual's birth date is crucial to construct a binary variable for whether the individual has finished compulsory education on time. Therefore, the data used in this paper corresponds to the cross-section version of the Spanish Labour Force Survey.

A description of the variables used in the analysis (except for those that are straightforward to construct) is given below:

On time compulsory schooling graduation: dummy variable that equals 1 if the individual has graduated from compulsory education on time. I use the variable estud (called nform from 2000 onwards) to construct this variable. Individuals are classified as having graduated from compulsory education on time if they are reported under code 23 in the fourth quarter of the year they turn 16 . This corresponds to the lower secondary stage of education, which marks the end of compulsory education in Spain. Individuals classified as having achieved a qualification higher than compulsory education at 16 are also included in this category. This should be very uncommon given the age of the individuals. In fact, there are only 99 individuals (out of the initial 10284 individuals in the pooled sample) that fall in this category.

Not in Education at 16: dummy variable that equals 1 if the individual is not in education in the fourth quarter of the year she turns 16. This corresponds to individuals classified under option 3 in the variable named cursa.

Not in Education, Employment or Training at 16: dummy variable that equals 1 if the individual is not in education (see variable defined just above) and is not employed; in the fourth quarter of the year she turns 16. Employed individuals are those with a paid job (or that had already found a job) the week before the interview took place (i.e., any of the following variables (trarem, ausent, nuevem) equal to 1).

Main explanatory variable: dummy variable that equals 1 when the father has a permanent contract in 
the fourth quarter of the year the child turns 16 (values 2 and 3 of the variable $d u c o n t$ ). It takes value 0 when the father has a fixed-term contract instead.

The instrument - Regional subsidies available to convert fixed-term contracts into permanent contracts: The information on the amount of subsidies available to firms to convert fixed-term contracts into permanent contracts comes from Table A.1 in Barceló and Villanueva (2016) (see Figure 2). I follow these authors and use as an instrument the amount of subsidy available to convert fixed-term contracts into permanent contracts during the first two years at the firm (in thousands of year 2000 euros). Subsidies varied at the region, gender, age and year level. Therefore, for every father, I estimate the amount of subsidy available using the number of years at the current job, the age when he entered the firm and the region of residence (NUTS 2). Regional deflators of household gross disposable income have been constructed using the database BDMORES elaborated by the the Spanish Ministry of Finance.

National reforms: Father started contract after 1997 is a dummy variable equal to 1 if the current contract held by the father was signed on or after 1997. Father entered labour market after 1984 is a dummy variable that equals 1 if the father entered the labour market on or after 1984. The year the individual enters the labour market is constructed as follows: Year of observation-Age+Age finished studies.

Father's job related characteristics: Third order polynomial in tenure: Father's tenure is expressed in years and introduced as tenure, tenure squared and tenure cubed. Sectoral dummies are dummies corresponding to the sector of activity of the firm in which the father works. These are grouped into the following aggregated sectors: agriculture and extractive industries, manufacturing and energy, construction, services I (retail and hotels), services II (transport and communication, finance and renting activities), public administration, education and health, other services. Results are the same if instead I include the more detailed 1-digit dummies (16 dummies, 1 omitted) based on the variable act2. Mother's job characteristics are constructed in the same fashion.

Father's and mother's personal characteristics: Maximum education reached dummies are four dummies constructed using information in estud for whether the father/mother has primary education or less; has completed lower secondary education; has completed upper secondary education; or has completed tertiary education.

Other regional characteristics: Regional unemployment rate, age range student is the unemployment rate in the region of residence (NUTS 2), for the age range and gender of the student, and in the year of observation (regional unemployment rates by age groups and gender are obtained from the Spanish National Institute of Statistics.) Regional subsidies (age range student) is the amount available to hire workers in the age range of the students in their region of residence and year of observation (in thousands of year 2000 euros). 
Other variables: Year dummies are dummies for years 2000 to 2004 and Regional dummies are dummies at the NUTS-2 level.

\section{A2 The Spanish Household Panel}

The Spanish section of the European Household Panel is available from year 1994 to 2001 from the Spanish National Institute of Statistics. The dataset consists of a fixed panel of 7206 households (first wave). An individual questionnaire is completed by all the members in the household that are 16 years old or older the 1st of January of each wave. I match children with fathers, and use data of two samples: (1) fathers holding permanent or fixed-term contracts in the year their children turn 16 in the sample; (2) all fathers aged 34 to 65 . I use the raw information on perceived satisfaction with several aspects of their job that can be found in variables pe031 to pe037. Additional dummy variables include: maximum education level reached by the father (4 dummies, as above; coming from pt022); firm's sector of activity: 17 dummies coming from pe007b). More information on the classifications used to construct sector variables is given in the Anexo 2 clasificaciones file provided by the Spanish National Institute of Statistics. 


\section{Appendix B. A simple theoretical framework}

Consider a student in general education that is faced with the decision to choose how much effort, $e$, to devote to study. Assume that the student's utility while she is in school depends directly and positively on the grades obtained, $G$ (i.e., better grades entail more rewards from parents, for instance). The grade production function is determined by the level of effort supplied by the student: $G=g(e)$ and is supposed to be strictly increasing and concave in the level of effort. The effort that students devote to study entails a disutility, $d(e)$, which is supposed to be strictly increasing and convex. The student chooses the level of effort to maximise her utility:

$$
\max _{e} U(G, e)=g(e)-d(e)
$$

The first order condition for an interior solution is equal to: $g^{\prime}(e)=d^{\prime}(e)$. In order to introduce heterogeneity into this framework, I follow Card (1999) by assuming that the marginal rate of return to effort is given by $g^{\prime}(e)=\beta_{i}(e)=b_{i}-k_{1} e$, and the marginal cost of effort is given by $d^{\prime}(e)=\delta_{i}=$ $r_{i}+k_{2} e$. Both are linear functions with person-specific intercepts and homogeneous slopes (with $k_{1} \geq 0$ and $k_{2} \geq 0$ ). Variation in $b_{i}$ could be seen as capturing variation in the inputs affecting the production function for cognitive achievement (see Todd and Wolpin (2003)). Variation in $r_{i}$ instead can be seen as different tastes for effort. The optimal level of effort under heterogeneity is then given by:

$$
e_{i}^{*}=\frac{b_{i}-r_{i}}{k_{1}+k_{2}}
$$

where a necessary condition for the equilibrium to exist with non-negative levels of effort is that $b_{i} \geq r_{i}$. The student completes education on time if her effort is above a certain level, $\bar{e}$, that leads grades to be above the 'passing' threshold, $\bar{g}$ : Graduation $16=1\left[e_{i}^{*} \geq \bar{e} \equiv G_{i} \geq \bar{g}\right]$.

Potentially bigger effects for compliers: If the inputs affected by contract type (like father's income, father's feelings of job insecurity, etc.) are at a disproportionately low/'bad' level for compliers prior to being induced by the instrument to obtain a permanent contract, then, assuming concavity of the grade production function, the increase in the quality of the inputs associated with obtaining a permanent contract for compliers entails a bigger increase in grades in this subpopulation. Likewise, the type of contract held by the father could be affecting work attitudes of the children. In the social psychology literature, Lim and Leng Loo (2003) find that perceived parental job insecurity has a negative effect on youth's self-efficacy and work attitudes. Going from a fixed-term to a permanent contract for compliers could entail, therefore, a bigger reduction in the disutility of effort for affected children, given 
convexity of the cost function. These two mechanisms together could explain the bigger impact found for compliers. 